\title{
Synthesis of Aryl(di)azinylmethanes and Bis(di)azinylmethanes via Transition- Metal-Catalyzed Cross-Coupling Reactions
}

\author{
Johan De Houwer, Bert U. W. Maes* \\ Organic Synthesis, Department of Chemistry, University of Antwerp, Groenenborgerlaan 171, 2020 Antwerp, Belgium \\ Fax +32(3)2653233; E-mail: bert.maes@uantwerpen.be \\ Received: 11.04.2014; Accepted after revision: 05.05.2014
}

\begin{abstract}
Aryl(di)azinyl- and bis(di)azinylmethane motifs are important as they are found in a number of pharmaceuticals and their precursors. An exhaustive overview of transition metal-catalyzed cross-coupling reactions for their synthesis has been provided.

1 Introduction

2 Reaction of(Di)azinyl (Pseudo)halides with Benzyl Organometallic Reagents

2.1 Organozinc Reagents - Negishi Reaction

2.2 Organoindium Reagents

2.3 Organoaluminum Reagents

2.4 Organotin Reagents - Migita-Kosugi-Stille Reaction

2.5 Organoboron Reagents - Suzuki-Miyaura Reaction

2.6 (Di)azinyl Methyl Thioether Reagents

3 Reaction of (Di)azinyl Organometallic Reagents with Benzyl (Pseudo)halides

3.1 Organomagnesium Reagents - Kumada Reaction

3.2 Organoaluminum Reagents

3.3 Organoboron Reagents - Suzuki-Miyaura Reaction

4 Reaction of (Di)azinylmethyl Halides with Aryl Organometallic Reagents

4.1 Organoboron Reagents - Suzuki-Miyaura Reaction

5 Reaction of Methyl(di)azine Reagents with Aryl Halides

5.1 Pre-activation of Methyl(di)azines

5.2 In Situ Pre-activation of Methyl(di)azines

5.3 Direct Arylation of Methyl(di)azines

6 Reaction of (Di)azine N-Oxides with Benzyl (Pseudo)halides

7 Conclusion
\end{abstract}

Key words: heterocycles, transition metals, cross-coupling, palladium, nickel

\section{$1 \quad$ Introduction}

Transition-metal-catalyzed cross-coupling reactions are nowadays widely accepted as a general tool for the construction of carbon-carbon bonds and already appear in educational chemistry textbooks. Starting from the early 1970s, the cross-coupling reactions (mediated mainly by palladium) evolved from using stoichiometric amounts of

SYNTHESIS 2014, 46, 2533-2550

Advanced online publication: 15.09 .2014

DOI: 10.1055/s-0034-1379025; Art ID: ss-2014-e0237-r

C Georg Thieme Verlag Stuttgart · New York the transition metal to requiring only catalytic amounts. While transition-metal-catalyzed transformations of aryl (pseudo)halides involving formation of (un)symmetrical biaryls have already gained a lot of attention and have been reviewed thoroughly, ${ }^{1}$ the synthesis of (un)symmetrical diphenylmethanes has gained less attention. A 2008 review by Bruneau summarized the functionalization of benzylic systems by palladium catalysis. ${ }^{2}$ Diarylmethane skeletons are usually prepared by palladium or nickel catalysis using arylboronic acids and benzyl (pseudo)halides [Suzuki-Miyaura reaction] or with (in situ formed) benzylzinc species and aryl (pseudo)halides [Negishi reaction] as coupling partners. Examples by Bedford and Gosmini have shown that even catalytic amounts of base metals (iron or cobalt catalysts) are applicable as catalysts for the synthesis of diarylmethanes. ${ }^{3}$

The syntheses of aryl(di)azinylmethanes rely mostly on analogous strategies. Halogenated (di)azines, for instance, react with benzyl organometallic species, such as benzylzinc bromide or benzyltributylstannane. A new and recent approach uses methyl(di)azines as such to prepare aryl(di)azinylmethanes, although (in situ) stoichiometric pre-activation is usually necessary. Stoichiometric preactivation can involve the use of strong bases $(\mathrm{BuLi}$, $\mathrm{TMPZnCl} \cdot \mathrm{LiCl}$ ) followed by transformation of the carbanion into more stable reagents that can be isolated or, in the case of $\mathrm{TMPZnCl} \cdot \mathrm{LiCl}$, directly used in a crosscoupling reaction. However pre-activation can also mean quaternization of the (di)azine nitrogen, like the formation of $N$-oxides or $N$-iminopyridinium ylides. Methyl(di)azines, such as 2- and 4-methylpyridine, are interesting starting materials as they appear in bone oil or can be easily synthesized via condensation reactions of acetaldehyde and ammonia. ${ }^{4}$ Aryl(di)azinylmethane motifs and their methylene substituted derivatives are economically very important as they are found in the structure of a number of pharmaceuticals or their precursors (Figure 1). ${ }^{5}$ Several methylene functionalization protocols starting from aryl(di)azinylmethanes have therefore been developed. ${ }^{6}$ Probably the most known pharmaceutical based on the aryl(di)azinylmethane entity is mefloquine (Lariam $\left.{ }^{\circledR}\right)$ (1), an antimalarial that, despite its known cytotoxicity, is still widely used in malaria prevention. ${ }^{5}$ Other examples containing the aryl(di)azinylmethane skeleton are the $1^{\text {st }}$ and $2^{\text {nd }}$ generation antihistamines carbinoxamine (2), bepotastine (3), doxylamine (4) and acrivastine (5), the $\beta_{2}$-adrenergic agonist rimiterol (6), the anxiolytic bromazepam 
<smiles>O[C@H](c1cc(C(F)(F)F)nc2c(C(F)(F)F)cccc12)C1CCCCN1</smiles><smiles>CNCCOC(c1ccc(Cl)cc1)c1ccccn1</smiles><smiles>Oc1ccc(C(O)C2CCCCN2)cc1O</smiles><smiles>O=C1CN=C(c2ccccn2)c2cc(Br)ccc2N1</smiles>

rimiterol (6) $\beta_{2}$-agonist bromazepam (7)
anxiolytic<smiles>CC(=O)CCCN1CCC(OC(c2ccc(Cl)cc2)c2ccccn2)CC1</smiles>

bepotastine (3) antihistamine<smiles>CN(C)CCOC(OCc1ccccc1)c1ccccn1</smiles>

doxylamine (4) antihistamine<smiles>Cc1ccc(C(=CCN2CCCC2)c2cccc(C=CC(=O)O)n2)cc1</smiles>

acrivastine (5) antihistamine

Figure 1

(7), the antibiotic trimethoprim (8) and the anti-psychotic lenperone (9). ${ }^{5}$

This review gives an overview of all transition-metalcatalyzed coupling reactions that provide aryl(di)azinylmethane or bis(di)azinylmethane entities. Their annulated systems, like quinolines, quinazolines, quinoxalines, phthalazines, cinnolines, naphthyridines, purines, etc., are not systematically covered as they mostly rely on protocols analogous to those of the parent (di)azine.

\section{$2 \quad$ Reaction of (Di)azinyl (Pseudo)halides with Benzyl Organometallic Reagents}

\subsection{Organozinc Reagents - Negishi Reaction}

In 1977, Negishi and Jutand independently communicated the first examples of transition-metal-catalyzed crosscoupling reactions using organozinc reagents. ${ }^{7}$ While Jutand used the Reformatsky reagent ethyl bromozincacetate for nickel- and palladium-catalyzed coupling reac-

\section{Biographical sketches}
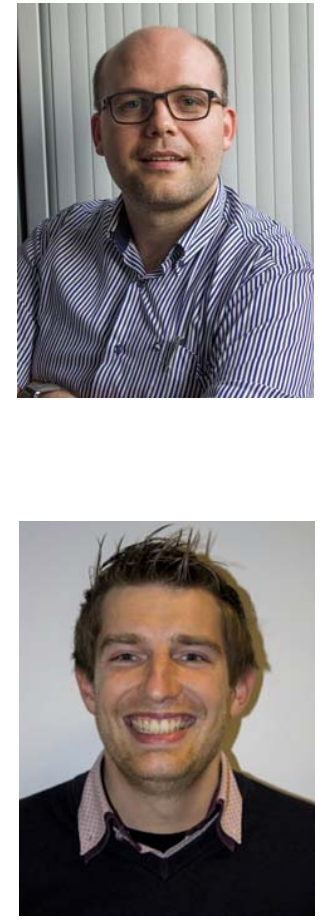

Bert Maes was educated at the University of Antwerp. In 2001 he received a postdoctoral fellowship of the National Science Foundation (FWO) in Belgium to allow his transition to an independent academic career. In 2003 he was appointed as an Assistant Professor (docent) in the Department of

Chemistry at the University of Antwerp and in 2008 promoted to the Associate Professor (hoofddocent) rank. In 2010 he worked in the group of Prof. Anny Jutand (CNRS) at the École Normale Supérieure in Paris studying fundamental mechanisms in catalysis. In January 2014 he was pro-

Johan De Houwer obtained his M.Sc. degree (licentiaat) in chemistry at the University of Antwerp in 2007. Under the supervision of Prof. Bert Maes he received his $\mathrm{PhD}$ in 2013. His moted to Professor (hoogleraar) and currently holds a research professorship. His research focuses on heterocyclic chemistry, organometallic chemistry, sustainable chemistry and homogeneous catalysis. $\mathrm{He}$ is an author of 95 publications, 4 book chapters and 3 patents.

His scientific interests are mainly focused on transition-metal-catalyzed (crosscoupling) reactions and heterocyclic chemistry. 
tions with aryl halides, Negishi used aryl- and benzylzinc species for the synthesis of unsymmetrical diaryls and diarylmethanes using the same transition metals as catalysts. Since then, many research groups have adapted the conditions reported by Negishi for the synthesis of (unsymmetrical) diphenylmethanes, as well as arylheteroarylmethanes, including aryl(di)azinylmethanes.

In 2000, Worthington reported the synthesis of 2-(6-benzylpyridin-2-yl)pyrimidines, which can be used as broadspectrum fungicides. ${ }^{8}$ The key intermediates, 2-(6-bromopyridin-2-yl)pyrimidines 11, were synthesized in multigram quantities by a palladium-catalyzed Negishi coupling of (6-bromopyridin-2-yl)zinc chloride with a 2bromopyrimidine. In the next step, 11a or 11b was crosscoupled with a benzylzinc reagent (obtained via the direct insertion of magnesium into a functionalized benzyl chloride 10, followed by transmetallation with zinc chloride) in the presence of a catalytic amount of tetrakis(triphenylphosphine)palladium, in tetrahydrofuran under reflux, to afford the required 2-(6-benzylpyridin-2-yl)pyrimidines 12a-e in moderate to good yields (Scheme 1).

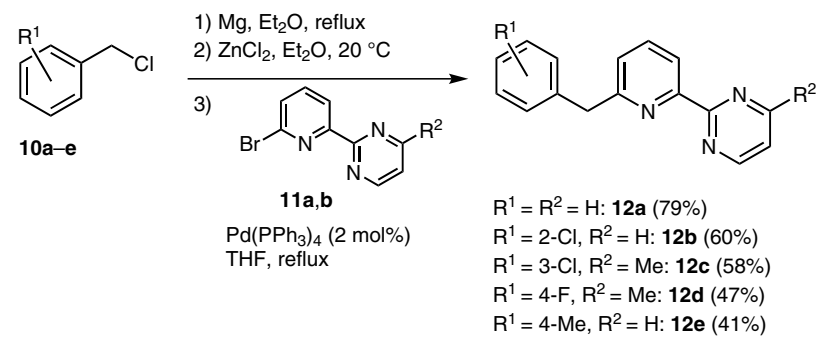

Scheme 1

In their study on thermally activated tautomerization processes in 2-(2,4-dinitrobenzyl)pyridine derivatives, Eichen and co-workers prepared 2-benzylpyridine substrates. ${ }^{9}$ 2-Benzyl-4-methylpyridine (15a) and 2-benzyl5-methylpyridine (15b) were prepared by a Negishi coupling of benzylzinc bromide, obtained via the direct insertion of zinc into benzyl bromide (13a), with 2-bromo-4methylpyridine (14a) and 2-bromo-5-methylpyridine (14b), respectively (Scheme 2). The obtained products 15a,b were then converted into the required nitro-substituted substrates 16a,b via electrophilic nitration.

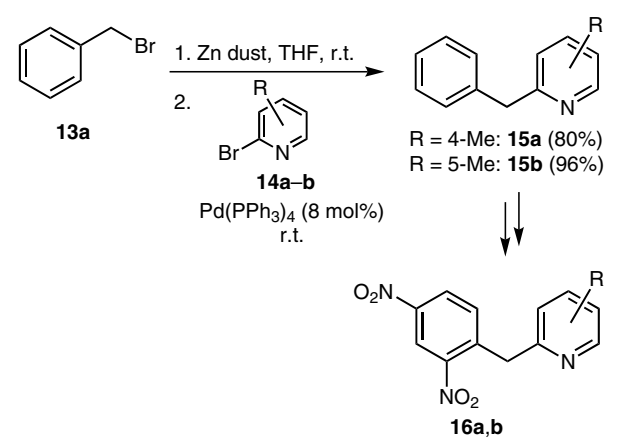

Scheme 2
During the synthesis of the natural product cleistopholine (19a) and two closely related analogues (19b,c), Krapcho and Ellis performed a nickel-catalyzed Negishi crosscoupling reaction on methyl 2-bromo-4-methylnicotinate (17) with benzylzinc bromides prepared by direct zinc insertion in the corresponding benzyl bromides 13a-c. ${ }^{10}$ The benzylpyridines 18a-c were then further transformed into the natural product and its analogues in four steps (Scheme 3).

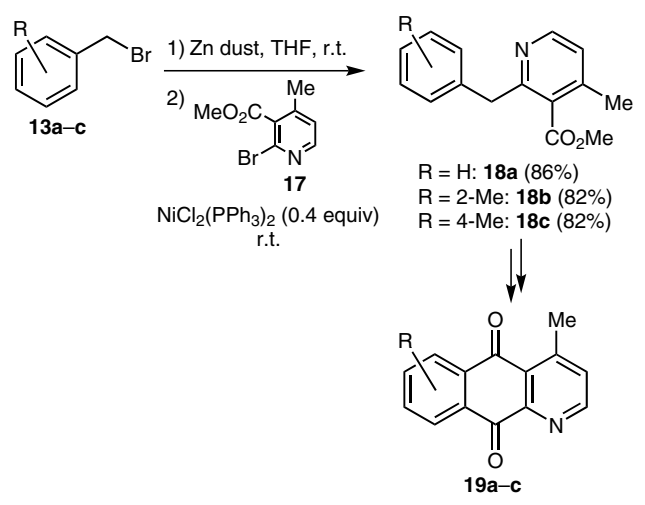

Scheme 3

In a 2002 publication, Andrés et al. reported the synthesis of 2-(dimethylaminomethyl)tetrahydroisoxazolo-pyridobenzazepine derivatives as $5-\mathrm{HT}_{2 \mathrm{C}}$ antagonists. ${ }^{11}$ The synthesis of one of these derivatives started with the palladium-catalyzed Negishi coupling of a Boc-protected (2-aminobenzyl)zinc bromide 13d with 2-bromo-3-(1,3dioxolan-2-yl)pyridine (20) in $60 \%$ yield (Scheme 4). Product 21 was then further converted into the desired 2-(dimethylaminomethyl)-2,3,3a,8-tetrahydroisoxazolo[3,2-a]pyrido[3,2-c][2] benzazepine (22) in five consecutive steps.

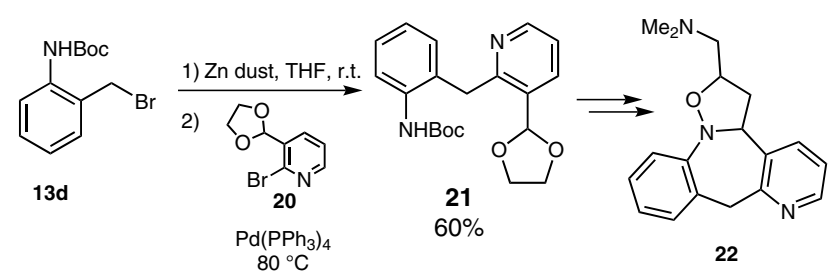

Scheme 4

In 2005, Kasatkin and co-workers noticed that 3,6-dichloropyridazines can react selectively with alkyl-, alkynyl-, aryl- and benzylzinc species to give the corresponding monosubstituted products. ${ }^{12}$ When 3,6-dichloropyridazine (25) was allowed to react with 1.6 equivalents of benzylzinc bromide (23a) or (3-chlorobenzyl)zinc chloride (24a) in the presence of a catalytic amount of tetrakis(triphenylphosphine)palladium, the resulting 6benzyl-3-chloropyridazines 26a,b were obtained selectively in moderate to good yields (Scheme 5). 


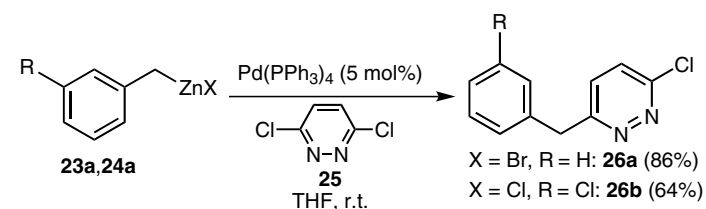

Scheme 5

The Hocek group published multiple papers on the synthesis of 6-substituted 2- and 3-pyridinyl $C$-(ribo)nucleosides. ${ }^{13}$ On 6-halo-2- and -3-pyridinyl $C$-(ribo)nucleoside substrates $\mathbf{2 7 a - c}$, they performed a set of transition-metalcatalyzed cross-coupling reactions, including a standard Negishi reaction with benzylzinc bromide (23a) (Scheme $6)$.

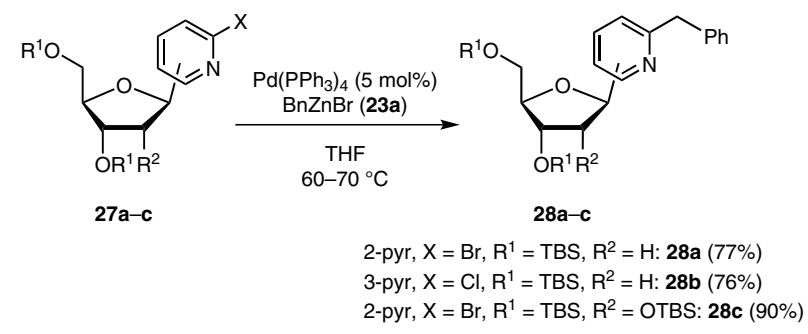

Scheme 6

In 2006, Walters reported the nickel-catalyzed Negishi coupling of amino-substituted halodiazines with alkyland benzylzinc reagents. ${ }^{14}$ The benzylzinc reagents were prepared by a nickel-catalyzed halogen-zinc exchange of the benzyl bromides (13a,e-h) with excess diethylzinc, a procedure that was developed earlier by Knochel. ${ }^{15} \mathrm{Em}$ ploying these conditions with 2-amino-6-chloropyrazine (29; $\mathrm{X}=\mathrm{CH}, \mathrm{Y}=\mathrm{N}$ ) and 3-amino-6-chloropyridazine (30; $\mathrm{X}=\mathrm{N}, \mathrm{Y}=\mathrm{CH}$ ) afforded the corresponding benzylated products $\mathbf{3 1}$ and $\mathbf{3 2 a - c}$ in moderate yields (Scheme 7).

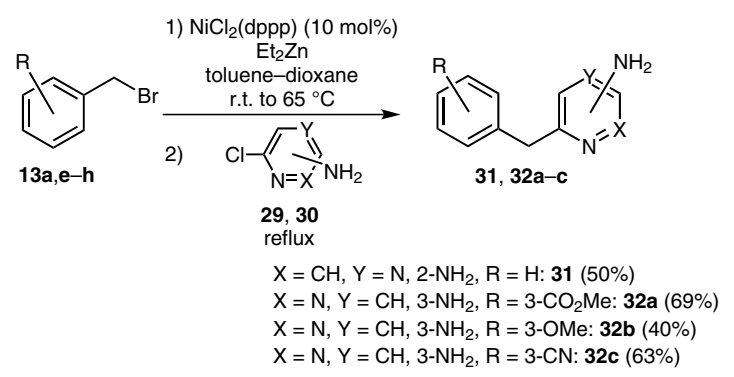

Scheme 7

During their studies on selective dopamine receptor agonists, Dutta and co-workers designed and synthesized a series of compounds that contained varying degrees of conformational constraint in the agonist moiety of the hybrid template. ${ }^{16}$ The synthesis of one of these compounds started with the nickel-mediated Negishi reaction of (3methoxybenzyl)zinc bromide, prepared by direct zinc insertion into 3-methoxybenzyl bromide (13g), with methyl 2-chloronicotinate (33), supplying the benzylated nicotinate 34 in $88 \%$ yield. Product 34 was then further converted into cis-1-[2-(4-phenylpiperazin-1-yl)ethyl]1,2,3,4,4a,5,10,10a-octahydrobenzo[g]quinolin-8-ol (35) in ten steps (Scheme 8).

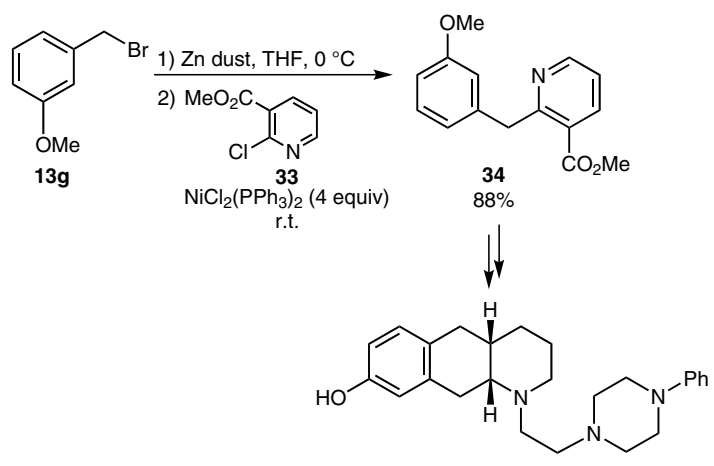

35

\section{Scheme 8}

In 2011, D'Angelo et al. reported the discovery and optimization of a series of benzothiazole phosphoinositide 3kinase inhibitors. ${ }^{17}$ During the structure-activity relationship (SAR) study, 4-(benzothiazol-6-yl)pyrimidine $\mathbf{3 6}$ was transformed into the benzylated analogue under standard cross-coupling conditions, providing 37 in a mere $11 \%$ yield (Scheme 9 ).

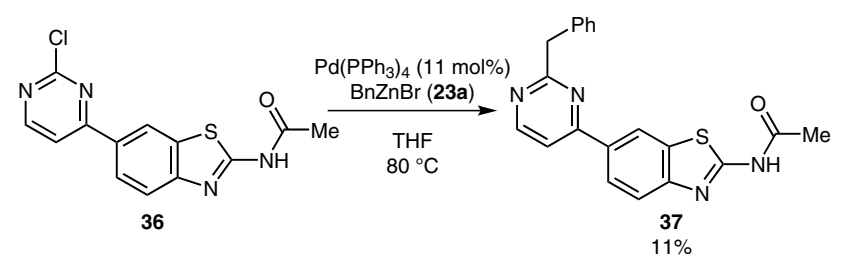

Scheme 9

During their efforts to identify novel $\mathrm{EP}_{1}$ antagonists for the treatment of inflammatory pain, Hall and co-workers reported the synthesis of a series of benzylated sodium picolinates 40. ${ }^{18}$ Ethyl 6-benzyl-2-picolinate 39 was obtained in $36 \%$ overall yield by reaction of zinc with benzyl bromide 13e, followed by a palladium-catalyzed Negishi reaction with ethyl 6-bromo-2-picolinate (38), deprotection with sodium methanethiolate and re-esterification. Alkylation of the phenol with different benzyl or alkyl halides followed by ester hydrolysis provided the desired substituted sodium picolinates 40 (Scheme 10).

After initial testing, the most active compound (40a) was subjected to more elaborate testing. Since the synthetic route depicted above was not suitable for large-scale synthesis of 42, an alternative route, applying a SuzukiMiyaura reaction as the key step, was developed. 2,6-Pyridinedicarboxylic acid (41) was first transformed in three steps into ethyl 6-chloromethyl-2-picolinate (42) in 70\% overall yield; $\mathbf{4 2}$ was then further converted into the desired sodium picolinate 40 a in $49 \%$ overall yield by a palladium-catalyzed Suzuki-Miyaura cross-coupling 


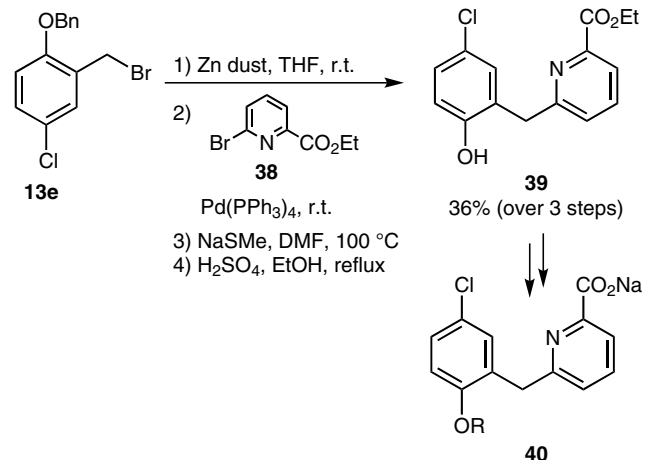

Scheme 10

reaction with boronic acid $\mathbf{4 3}$, followed by hydrolysis of the ester (Scheme 11).

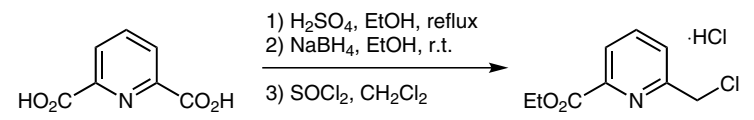

41

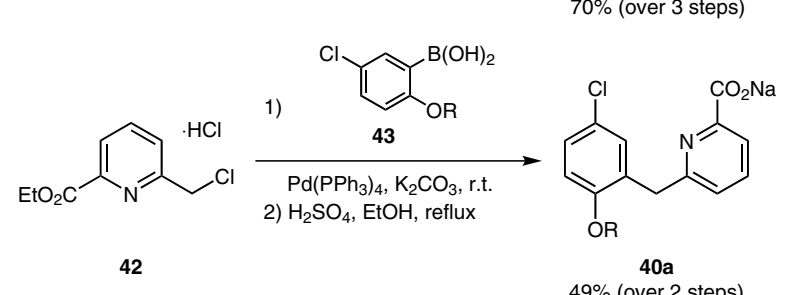

42<smiles>[18O]=Cc1cc(Cl)ccc1F</smiles>

\section{Scheme 11}

During their research on $6 H$-pyrido[1,2-b]pyridazin-6ones as potential p38 MAP kinase inhibitors, Tynebor et al. performed palladium-catalyzed Negishi reactions on 2,5-dibromopyridine (44) and 3,6-dichloropyridazine (25), employing (2,6-difluorobenzyl)zinc bromide (23b) as the organometallic reagent. ${ }^{19}$ The obtained halogenated benzylic coupling products $\mathbf{4 5 a} \mathbf{a}, \mathbf{b}$ were then transformed into the corresponding bromo- and chlorobicyclics $\mathbf{4 6 \mathbf { a } , \mathbf { b }}$ in three steps. Displacement of the chloro or bromo substituent by nucleophilic subsitution or by transition-metalcatalyzed reactions provided a set of functionalized products, thereby allowing a SAR study (Scheme 12).

During the last decade, Knochel has published numerous papers on Negishi cross-coupling reactions in organic synthesis, including the use of benzylzinc reagents for the synthesis of diphenylmethanes, benzylated (di)azines and bis(heteroaryl)methanes.

In 2008, the Knochel group published their first communication on transition-metal-catalyzed cross-coupling reactions of benzylzinc reagents with (hetero)aromatic (pseudo)halides. ${ }^{20}$ Functionalized benzylzinc chlorides

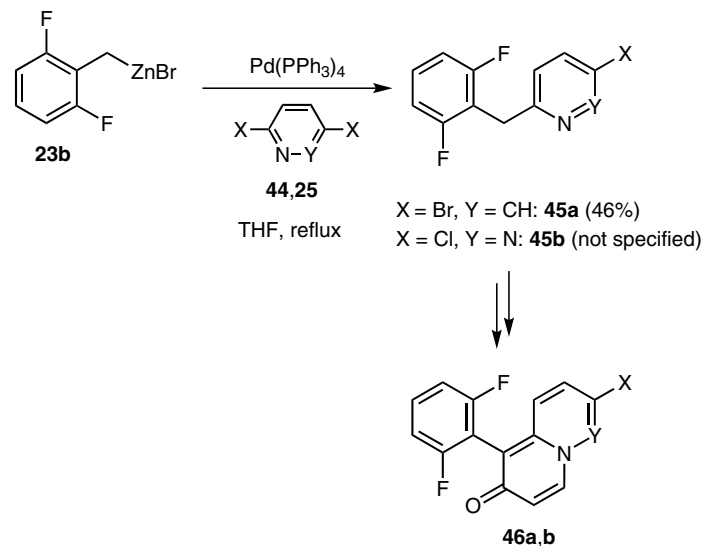

Scheme 12

47a-c were cross-coupled with (hetero)aryl chlorides, bromides and tosylates $\mathbf{4 8}-\mathbf{5 1}$ using nickel catalysis. The benzylzinc chlorides 47 were obtained from the corresponding benzyl chlorides by direct insertion with zinc in the presence of lithium chloride. ${ }^{21}$ The corresponding benzylated pyridines and pyrimidines 52-55 were obtained in moderate to excellent yields (Scheme 13).
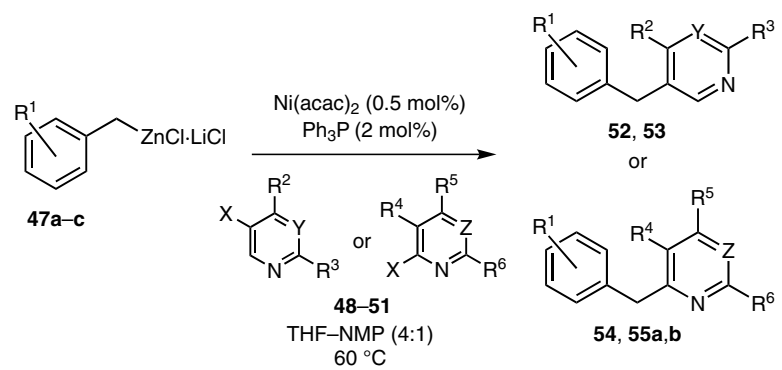

$$
\begin{aligned}
& \mathrm{R}^{1}=3,4,5-(\mathrm{OMe})_{3}, \mathrm{X}=\mathrm{Br}, \mathrm{Y}=\mathrm{N}, \mathrm{R}^{2}=\mathrm{R}^{3}=\mathrm{OMe}: \mathbf{5 2}(63 \%) \\
& \mathrm{R}^{1}=3-\mathrm{COBu}, \mathrm{X}=\mathrm{OTs}, \mathrm{Y}=\mathrm{CH}, \mathrm{R}^{2}=\mathrm{H}, \mathrm{R}^{3}=\mathrm{Me}: \mathbf{5 3}(84 \%) \\
& \mathrm{R}^{1}=3,4,5-(\mathrm{OMe})_{3}, \mathrm{X}=\mathrm{Cl}, \mathrm{Z}=\mathrm{N}, \mathrm{R}^{4}=\mathrm{H}, \mathrm{R}^{5}=\mathrm{R}^{6}=\mathrm{OMe}: \mathbf{5 4}(98 \%) \\
& \mathrm{R}^{1}=3-\mathrm{COBu}, \mathrm{X}=\mathrm{Cl}, \mathrm{Z}=\mathrm{CH}, \mathrm{R}^{4}=\mathrm{CO}_{2} \mathrm{Et}, \mathrm{R}^{5}=\mathrm{R}^{6}=\mathrm{H}: \mathbf{5 5 a}(90 \%) \\
& \mathrm{R}^{1}=3-\mathrm{COMe}, \mathrm{X}=\mathrm{Cl}, \mathrm{Z}=\mathrm{CH}, \mathrm{R}^{4}=\mathrm{CO}_{2} \mathrm{Et}, \mathrm{R}^{5}=\mathrm{R}^{6}=\mathrm{H}: \mathbf{5 5 b}(68 \%)
\end{aligned}
$$

\section{Scheme 13}

In the same year, a full paper was published regarding palladium- and nickel-catalyzed cross-couplings of unsaturated halides bearing functional groups with relatively acidic protons with organozinc reagents. ${ }^{22}$ Alkyl-, aryland benzylzinc reagents were, for instance, allowed to react with halogenated anilines, phenols, benzylamines and benzyl alcohols in the presence of catalytic amounts of palladium or nickel. In this manner, 3-amino-5-bromopyridine $(\mathbf{5 6} \mathbf{a} ; \mathrm{R}=\mathrm{H})$ and methyl 3-amino-5-bromopicolinate $\left(\mathbf{5 6} \mathbf{b} ; \mathrm{R}=\mathrm{CO}_{2} \mathrm{Me}\right)$ reacted with cyanobenzyl)zinc chloride (47d) and (4-fluorobenzyl)zinc chloride (47e), respectively, in excellent yields (Scheme 14). 


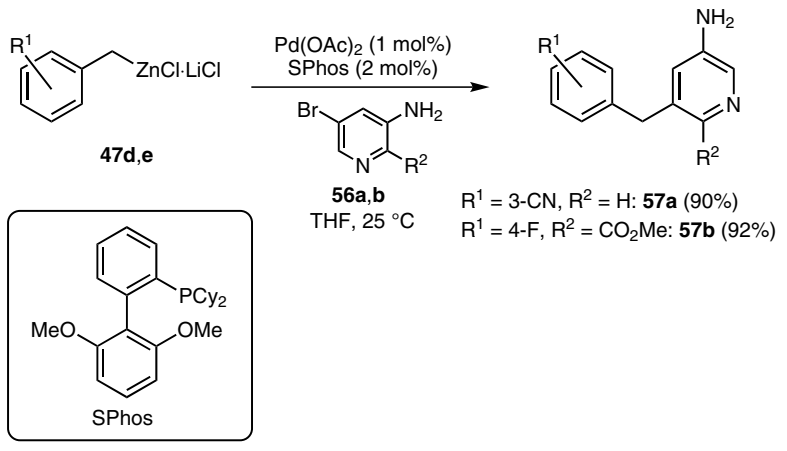

Scheme 14

More recently, Czarnocki and co-workers reported the synthesis of a series of substituted 4-benzylpyrimidines $\mathbf{6 1}$ and 2,6-dibenzylpyridines $\mathbf{6 2}$ and $\mathbf{6 3}{ }^{23}$ These compounds are well known as synthetic by-products in the illegal synthesis of amphetamine and its ring-substituted analogues. Commercially available benzylzinc reagents $\left[\mathrm{R}^{1}=\mathrm{H}, 4-\mathrm{F}, 2-\mathrm{OMe}, 3-\mathrm{OMe}, 4-\mathrm{OMe}, 2,5-(\mathrm{OMe})_{2}\right]$ and benzylzinc reagents $\left[\mathrm{R}^{1}=2-\mathrm{F}, 4-\mathrm{SMe}, 3,4,5-(\mathrm{OMe})_{3}\right]$ that were prepared according to the method of $\mathrm{Knochel}^{21}$ were cross-coupled with 4-bromopyrimidine (58), 2,6-dibromopyridine (59) and 2,6-dibromo-4-methylpyridine (60), respectively, using catalytic amounts of tetrakis(triphenylphosphine)palladium in toluene. The resulting (di)benzylated (di)azines 61-63 were obtained in low to good yields (Scheme 15).

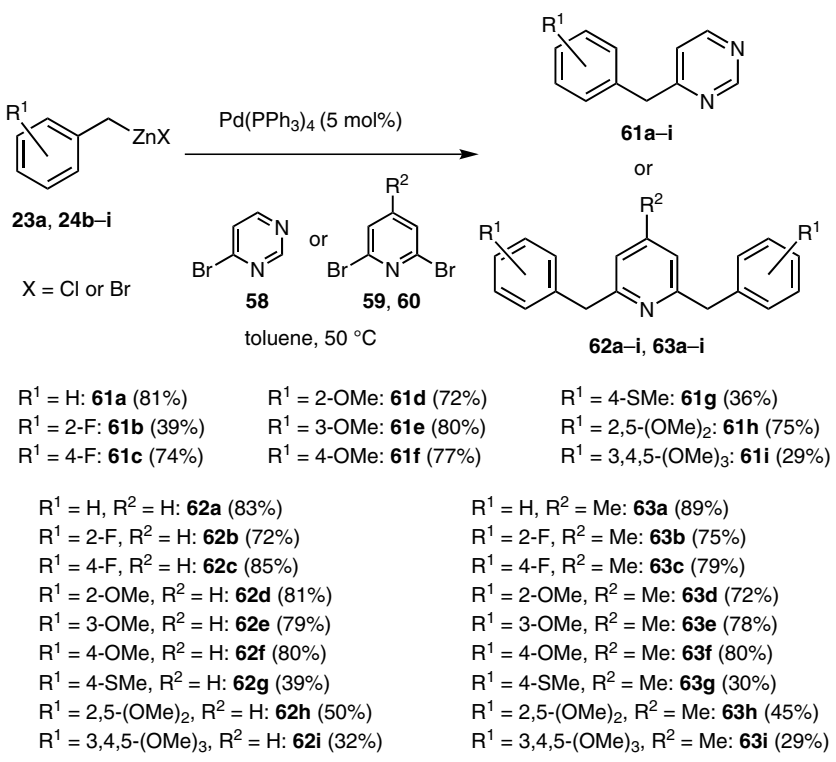

Scheme 15

\subsection{Organoindium Reagents}

In a 2009 communication, Chupak et al. reported a palladium-catalyzed cross-coupling reaction of benzylindium reagents with aryl iodides. ${ }^{24}$ The benzylindium reagents were prepared by direct insertion of indium into benzyl bromides in $N, N$-dimethylformamide at room temperature and were then coupled with a range of substituted aryl iodides by using a catalytic amount of tetrakis(triphenylphosphine)palladium, giving rise to a series of functionalized diphenylmethanes. In only one example, a heteroaryl bromide was used. In this particular case, (3methoxycarbonylbenzyl)indium bromide (64) was coupled with methyl 5-bromonicotinate (65), providing benzylpyridine 66 in a poor $21 \%$ isolated yield (Scheme 16).

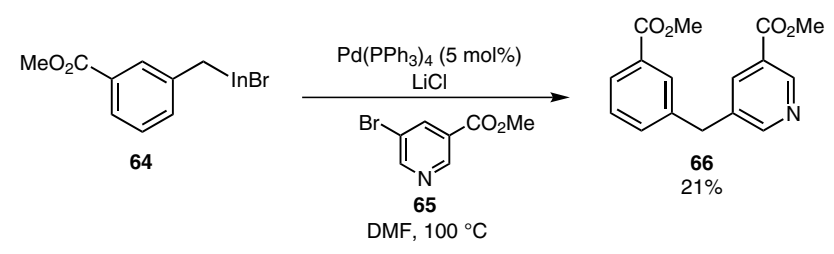

Scheme 16

\subsection{Organoaluminum Reagents}

A 2011 publication by Knochel and co-workers reported the use of organoalanes in cross-coupling reactions. Functionalized benzyl chlorides were transformed into benzyl aluminum sesquichlorides by reaction with aluminum powder in the presence of catalytic amounts ( $3 \mathrm{~mol} \%)$ of a metal chloride. ${ }^{25}$ From the metal chlorides that were tested $\left(\mathrm{PbCl}_{2}, \mathrm{BiCl}_{3}, \mathrm{TiCl}_{4}, \mathrm{InCl}_{3}\right)$, indium(III) chloride proved to be superior in terms of yield of the aluminum sesquichlorides, without formation of benzil (1,2-diphenylethane) dimers. These new benzyl organometallic species were then, for instance, cross-coupled with (hetero)aryl and allyl halides using a PEPPSI- $i$ Pr catalyst with zinc acetate as additive. The authors stated that the addition of stoichiometric amounts of zinc acetate appeared to be crucial in obtaining a cross-coupling reaction. They speculated that the acetate anion reduces the Lewis acidity of the aluminum species whereas the zinc cation favors the transfer of the aryl group to palladium. Under these conditions, (4-methoxybenzyl) chloride (10f) and (4-fluorobenzyl) chloride (10d) were first converted into the corresponding benzyl aluminum sesquichlorides and were then cross-coupled with ethyl 5-bromopyridine-3-carboxylate (67) and ethyl 4-iodo-2,6-dimethoxypyrimidine-5carboxylate (68), respectively, giving rise to the benzylated products 69 and 70 in good to excellent yields (Scheme 17). 


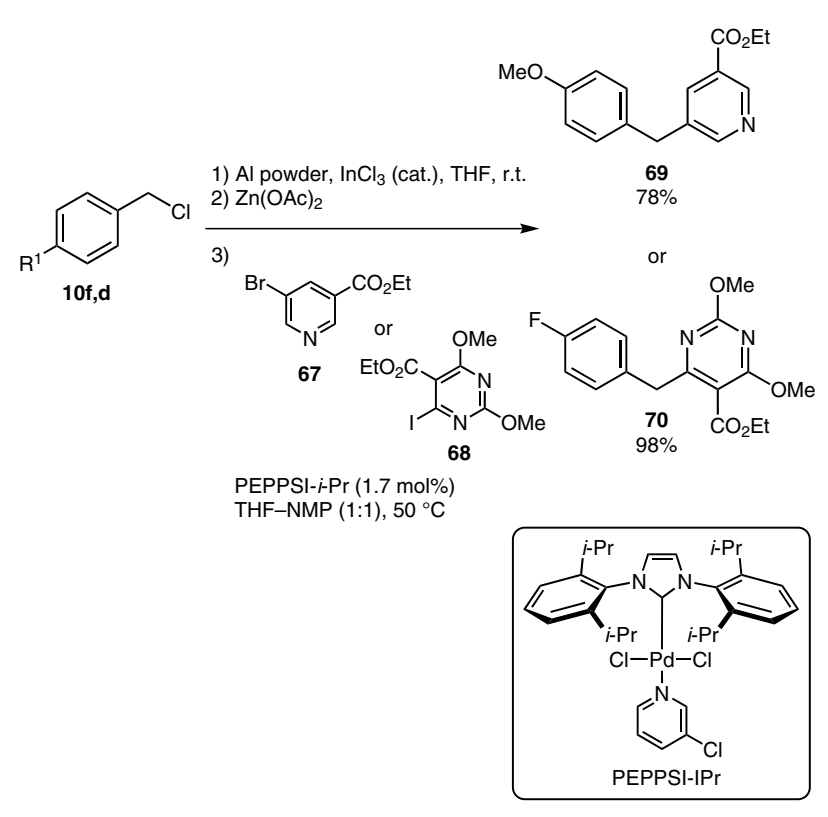

Scheme 17

\subsection{Organotin Reagents - Migita-Kosugi-Stille Reaction}

In 2006, Hirano and co-workers reported the bioluminescence of the calcium-activated photoproteins aequorin and obelin. ${ }^{26}$ They used a palladium-catalyzed MigitaKosugi-Stille reaction for the chemoselective coupling of 3,5-dibromo-6-methylpyrazin-2-amine (72) with benzyltributylstannane (71). The resulting benzylpyrazine $\mathbf{7 3}$ was obtained in $36 \%$ isolated yield and was then further converted into the desired pyrazine amide $\mathbf{7 4}$ in three steps (Scheme 18).

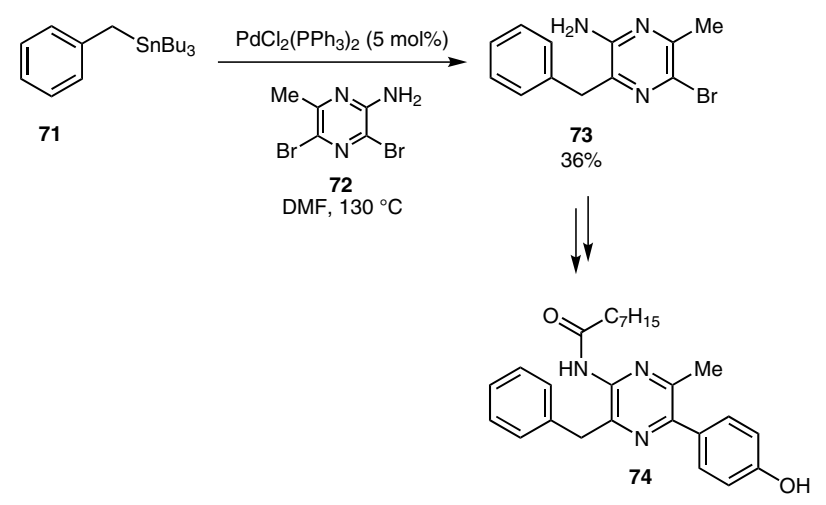

Scheme 18

\subsection{Organoboron Reagents - Suzuki-Miyaura Reaction}

In 2005, Flaherty et al. reported the use of commercially available $B$-benzyl-9-BBN (75) as the coupling partner in a palladium-catalyzed Suzuki-Miyaura reaction. ${ }^{27} \mathrm{Be}-$ sides the synthesis of a range of substituted diphenylmethanes, 2-benzylpyridine (77) and 2-benzylquinoline were also prepared. 2-Chloropyridine (76) was coupled with $\mathbf{7 5}$ in the presence of a catalytic amount of palladium(II) acetate and SPhos under anhydrous conditions, resulting in 2benzylpyridine (77) in 62\% isolated yield (Scheme 19).

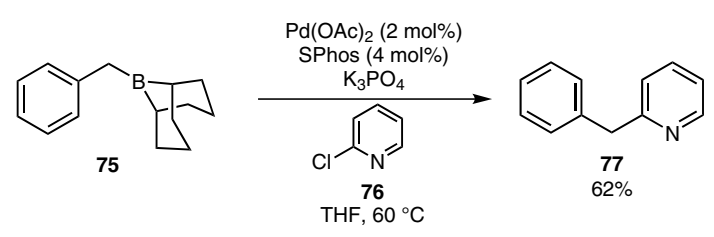

Scheme 19

Very recently, in 2014, Yudin and co-workers used benzylic and aliphatic $N$-methyliminodiacetyl (MIDA) boronates in a palladium-catalyzed Suzuki-Miyaura crosscoupling reaction with functionalized (hetero)aryl bromides. ${ }^{28}$ Tetrahedral boronates, like MIDA boronates and potassium trifluoroborates, circumvent possible side reactions (e.g., protodeborylation and $\beta$-hydride elimination) by coordinative saturation of the vacant $\mathrm{p}$-orbital of boron. 3-Bromo- and 5-bromo-2-methoxypyridine (79a,b) and 2-bromo-6-methoxypyridine (80) were coupled with $B$-benzyl MIDA boronate $\mathbf{7 8}$ in moderate to good yields (Scheme 20).

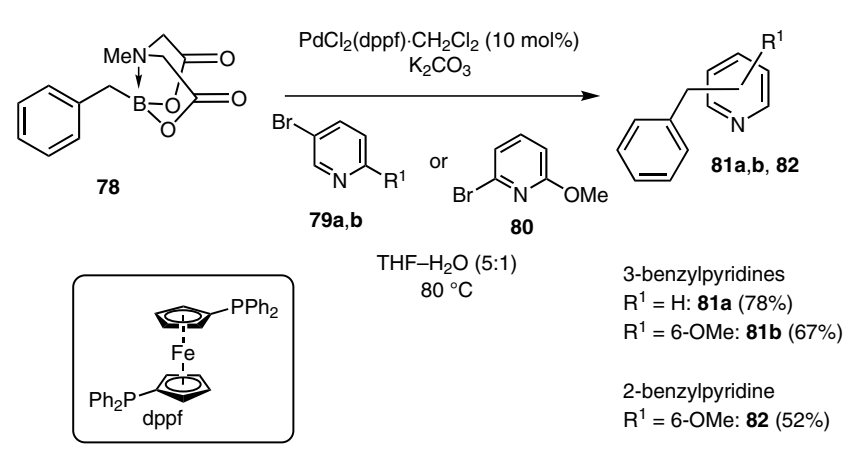

Scheme 20

\section{6 (Di)azinyl Methyl Thioether Reagents}

In 2000, Casalnuovo and co-workers found that methylthio-substituted nitrogen heteroarenes are viable substrates for palladium-catalyzed cross-coupling reactions with benzylzinc species. ${ }^{29}$ During their research on cereal herbicides, they envisioned that it should be possible for 4-chloro-2-(methylthio)-pyrimidines to react chemoselectively with benzylzinc species, with the methylthio blocking group kept intact during the catalysis. Subsequently, this group would be oxidized to the sulfone and displaced with various nucleophiles. Much to their surprise, however, they noticed that the palladium-catalyzed benzylation of either 4-chloro-5-methyl-2-(methylthio)pyrimidine (83) or 2-chloro-5-methyl-4-(methylthio)pyrimidine (84) gave the same major 2-benzylpyrimidine regioisomer $\mathbf{8 5}$ (Scheme 21), although yields were not specified. In both cases the $\mathrm{C}-2$ position proved to be more reactive towards oxidative addition than the C-4 position, also in the case of the methylthio substituent. Gas chromatographic anal- 
ysis of the Negishi reaction of $\mathbf{8 3}$ revealed two intermediate compounds 86 and 87 , which explains the outcome of the reaction (Scheme 22).

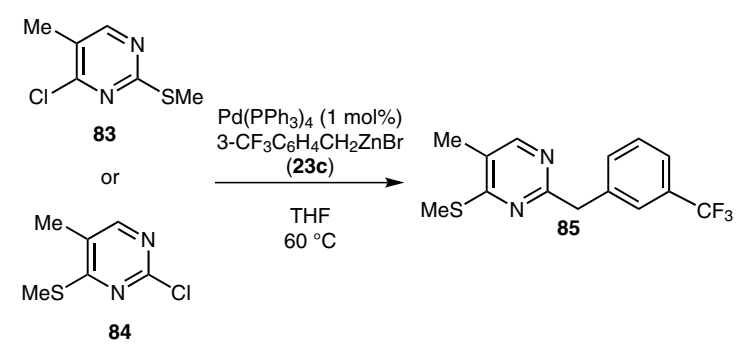

Scheme 21

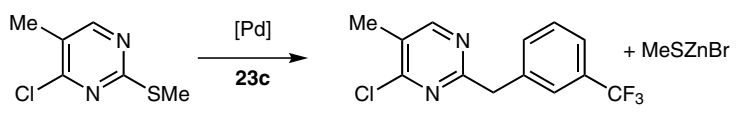

83

86<smiles>COc1ncc(C)c(Cl)n1</smiles>

83 87<smiles>COc1ncc(C)c(S(C)(=O)=O)n1</smiles>

85

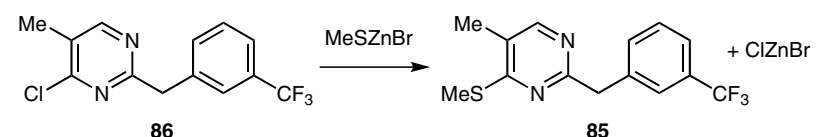

Scheme 22

While the related nickel- and palladium-catalyzed crosscoupling of Grignard reagents with methylthio-substituted nitrogen heteroarenes was already known at that time, this Negishi cross-coupling was unprecedented. After the necessary control experiments, the reaction scope was explored. In contrast to the aforementioned Kumada reactions, the authors noticed that the methylthio group must occupy a position activated for nucleophilic substitution in order for cross-coupling to occur. While 2- and 4(methylthio)pyridine (88 and $\mathbf{8 9}$ ) underwent the crosscoupling with benzylzinc bromide (23a) smoothly, 3(methylthio)pyridine (90) and thioanisole (91) gave no cross-coupled product. Other methylthio-substituted nitrogen heteroarenes like (methylthio)pyrazine (92) and 2(methylthio)pyrimidine (93), were readily converted into the corresponding benzylated products in good yields (Scheme 23).

To further investigate the unexpected regioselectivity of 4-chloro-5-methyl-2-(methylthio)pyrimidine (83), the authors treated 2,4-bis(methylthio)pyrimidine $\left(\mathbf{9 9} ; \mathrm{R}^{1}=\mathrm{H}\right)$ with an excess of benzylzinc bromide (23a) (Scheme 24). By performing gas chromatographic analysis of the initially formed products (i.e., at low conversion), they observed that the 2-methylthio group was 30 times more reactive than the 4-methylthio group (formation of $\mathbf{1 0 0}>$

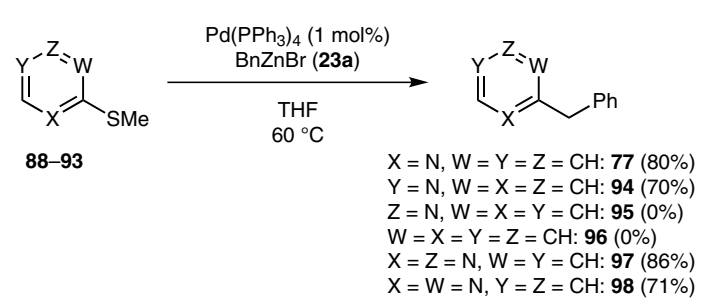

Scheme 23

101). With the methyl substituent ortho to the 4-methylthio group, for instance in the cross-coupling of 5-methyl-2,4-bis(methylthio)pyrimidine $\left(87 ; \mathrm{R}^{1}=\mathrm{Me}\right)$ with an excess of 3-(trifluoromethyl)benzyl zinc bromide (23c), the regioselectivity was increased even further, favoring benzylation in the C-2 position in a 500:1 ratio (formation of $85>$ 102). Interestingly, when the Negishi reaction was applied to sulfone 103, benzylation only took place at the 4-chloro group, even in the presence of two equivalents of the benzylzinc reagent (Scheme 25). These results offer new flexibility in designing regioselective synthesis routes for substituted heterocycles.

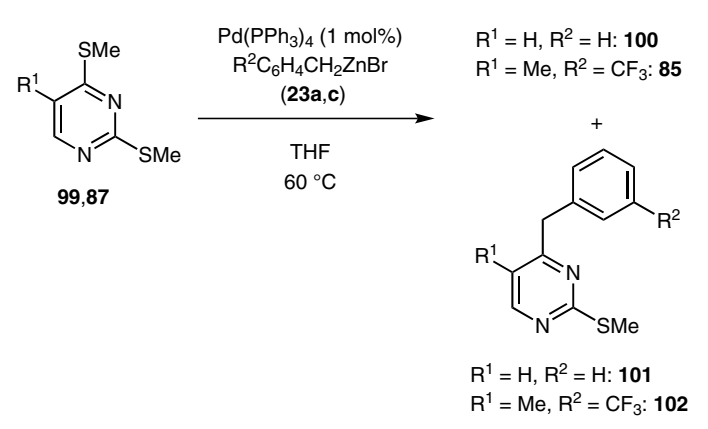

Scheme 24
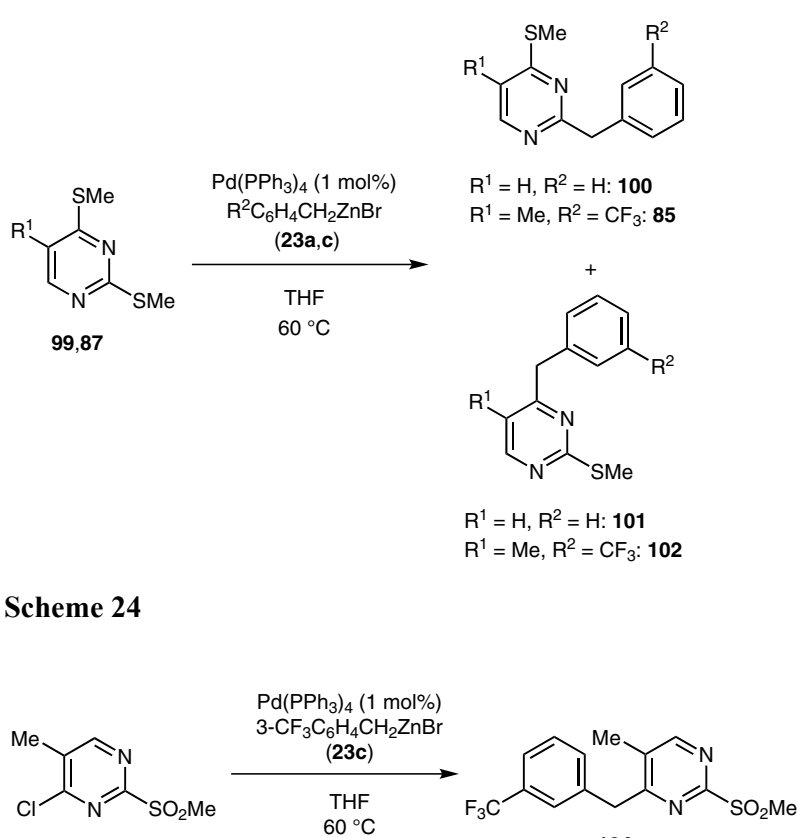

103

104

Scheme 25

In 2009, the Knochel team reported a catalytic system that allowed for a palladium-catalyzed Negishi cross-coupling reaction with thiomethyl-substituted nitrogen heteroarenes at room temperature..$^{30} \mathrm{~A}$ set of substituted (benzo)(di)azinyl and (benzo)azolyl methyl thioethers were allowed to react with functionalized aryl-, alkyl- and benzylzinc reagents in tetrahydrofuran in the presence of catalytic amounts of palladium(II) acetate and SPhos. In this fashion, ethyl 4-[2-(methylthio)pyrimidin-4-yl]benzoate (105a), 4-methyl-2-(methylthio)pyrimidine (105b), 2(methylthio)nicotinonitrile (106) and 3-methoxy-6- 
(methylthio)pyridazine (107) were cross-coupled with functionalized benzylzinc reagents 47 , affording the benzylated (di)azines 108a,b, 109, and 110 in good yields (Scheme 26).
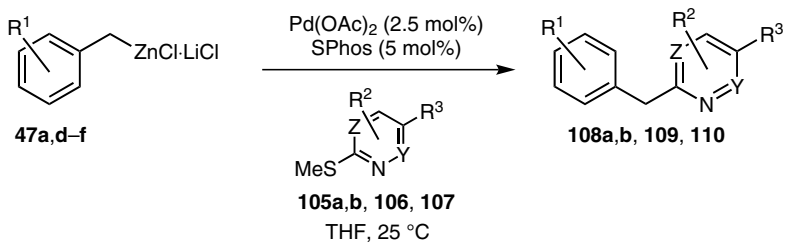

108a,b, 109, 110 THF, $25^{\circ} \mathrm{C}$

$\mathrm{R}^{1}=3,4,5-(\mathrm{OMe})_{3}, \mathrm{Y}=\mathrm{CH}, \mathrm{Z}=\mathrm{N}, \mathrm{R}^{2}=4-\left(4-\mathrm{EtCO}_{2} \mathrm{C}_{6} \mathrm{H}_{4}\right), \mathrm{R}^{3}=\mathrm{H}: \mathbf{1 0 8 a}(88 \%)$

$R^{1}=3-\mathrm{CO}_{2} \mathrm{Et}, \mathrm{Y}=\mathrm{CH}, \mathrm{Z}=\mathrm{N}, \mathrm{R}^{2}=4-\mathrm{Me}, \mathrm{R}^{3}=\mathrm{H}: \mathbf{1 0 8 b}(73 \%)$

$\mathrm{R}^{1}=4-\mathrm{F}, \mathrm{Y}=\mathrm{CH}, \mathrm{Z}=\mathrm{CH}, \mathrm{R}^{2}=3-\mathrm{CN}, \mathrm{R}^{3}=\mathrm{H}: 109(83 \%)$

$\mathrm{R}^{1}=3-\mathrm{CN}, \mathrm{Y}=\mathrm{N}, \mathrm{Z}=\mathrm{CH}, \mathrm{R}^{2}=\mathrm{H}, \mathrm{R}^{3}=\mathrm{OMe}: \mathbf{1 1 0}(71 \%)$

\section{Scheme 26}

The authors were also able to do selective one-pot crosscoupling reactions at room temperature. Similar to the chemoselectivity observed by Casalnuovo, 2-bromo-4(methylthio)pyrimidine (111) reacted selectively with (4methoxybenzyl)zinc chloride $(\mathbf{4 7 g})$ at room temperature, with bis(dibenzylideneacetone)palladium(0) and tris(2furyl)phosphine (tfp) as precatalyst system, then underwent a second Negishi reaction with 4-(ethoxycarbonyl)phenylzinc iodide (47h), with a palladium(II) acetate and SPhos precatalyst (Scheme 27). In this way the resulting 2,4-difunctionalized pyrimidine 112 was obtained regioselectively in $68 \%$ overall yield. Alternatively, under the same conditions, 4-iodo-2-(methylthio)pyrimidine (113) was transformed in the regioisomeric pyrimidine 114 in $80 \%$ yield over the two steps.
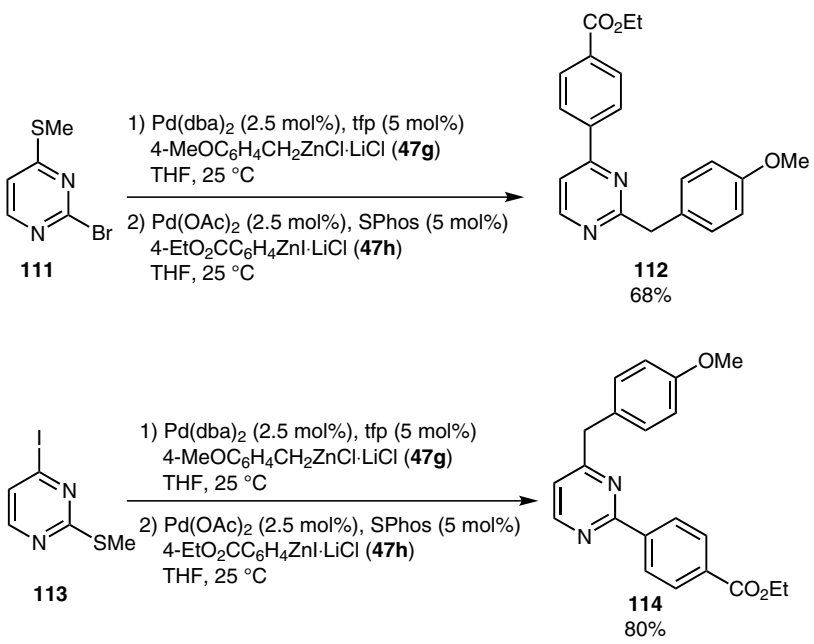

Scheme 27

One year later, a follow-up paper was published by the same research group regarding the use of a less expensive nickel catalyst in place of the palladium(II) acetate and SPhos catalyst system. ${ }^{31}$ Optimization of the reaction conditions revealed that nickel(II) acetylacetonate in combination with DPE-Phos gave the best results. With a low catalyst loading of $1 \mathrm{~mol} \%$, and $2 \mathrm{~mol} \%$ of the ligand, sev- eral substituted (di)azinyl and azolyl methyl thioethers were allowed to react with functionalized aryl-, alkyl- and benzylzinc reagents in tetrahydrofuran at room temperature. Under the optimized conditions, 2-(methylthio)nicotinonitrile (106), 3-methoxy-6-(methylthio)pyridazine (107) and 4-methyl-2-(methylthio)pyrimidine (105a) were cross-coupled with functionalized benzylzinc reagents 47, affording the benzylated (di)azines 115a,b, 116 and 117 in good to excellent yields (Scheme 28).

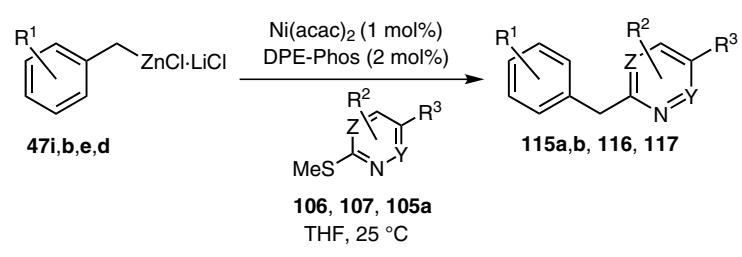

$\mathrm{R}^{1}=3-\mathrm{CF}_{3}, \mathrm{Y}=\mathrm{CH}, \mathrm{Z}=\mathrm{CH}, \mathrm{R}^{2}=3-\mathrm{CN}, \mathrm{R}^{3}=\mathrm{H}: \mathbf{1 1 5 a}(73 \%)$ $R^{1}=3-C O B u, Y=C H, Z=C H, R^{2}=3-C N, R^{3}=H: 115 b(79 \%)$ $R^{1}=4-F, Y=N, Z=C H, R^{2}=H, R^{3}=O M e: 116(74 \%)$ $\mathrm{R}^{1}=3-\mathrm{CN}, \mathrm{Y}=\mathrm{CH}, \mathrm{Z}=\mathrm{N}, \mathrm{R}^{2}=4-\mathrm{Me}, \mathrm{R}^{3}=\mathrm{H}: 117(94 \%)$

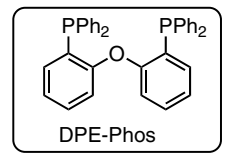

\section{Scheme 28}

In the same year, Knochel and co-workers also published a study regarding the scalability of the Negishi crosscoupling protocol with thiomethyl-substituted nitrogen heteroarene substrates. ${ }^{32}$ For instance, using the nickelcatalyzed protocol mentioned above, the authors carried out the reaction of (4-methoxybenzyl)zinc chloride $(\mathbf{4 7 g})$ with (methylthio)pyrazine (92) using $2.5 \mathrm{~mol} \%$ nickel(II) acetylacetonate and $5.0 \mathrm{~mol} \%$ DPE-Phos in tetrahydrofuran at room temperature on a $10 \mathrm{mmol}$ scale. The resulting (4-methoxybenzyl)pyrazine (118) was obtained in $84 \%$ isolated yield (Scheme 29).

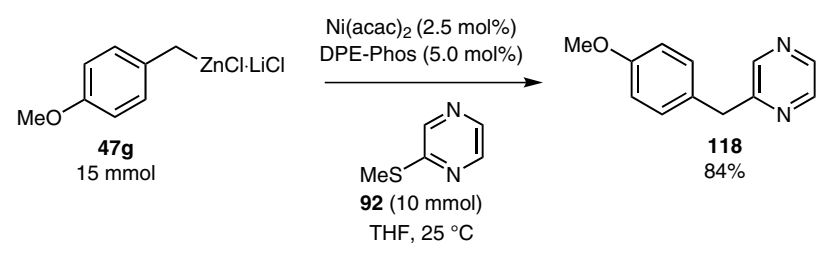

Scheme 29

\section{Reaction of (Di)azinyl Organometallic Reagents with Benzyl (Pseudo)halides}

\subsection{Organomagnesium Reagents - Kumada Reaction}

In 2006, Knochel's research group reported a coppercatalyzed cross-coupling reaction of arylmagnesium reagents with benzyl phosphates. ${ }^{33}$ A range of unsymmetrical diphenylmethanes were prepared, as well as the synthetic antibiotic drug trimethoprim (8). For this purpose, 
5-bromo-2,4-di(tert-butoxy)pyrimidine (119) was first magnesiated with isopropylmagnesium chloride-lithium chloride complex, then underwent a copper-catalyzed cross-coupling reaction with diethyl 3,4,5-trimethoxybenzyl phosphate (120). The resulting benzylated pyrimidine 121 was obtained in $81 \%$ yield and was then further transformed into antibiotic 8 in three steps (Scheme 30).
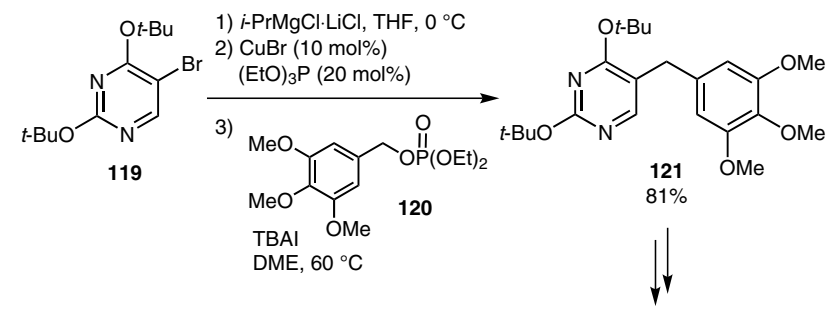<smiles>COc1cc(Cc2cnc(N)nc2N)cc(OC)c1OC</smiles>

Scheme 30

\subsection{Organoaluminum Reagents}

Early in 2014, Zhou published a paper on the palladiumcatalyzed cross-coupling of heteroaromatic dialkylalane etherates $\left[\mathrm{ArAlR}_{2}\left(\mathrm{OEt}_{2}\right)\right]$ with (hetero)aromatic $(\mathrm{R}=\mathrm{Me})$ and benzylic halides $(\mathrm{R}=\mathrm{Et}) .{ }^{34}$ The organoaluminum compounds 122a,b were prepared by lithiation of the corresponding heteroaryl bromide with butyllithium in diethyl ether, followed by quenching with dimethyl- or diethylaluminum chloride. For simplicity reasons, the organoalanes are represented as (heteroaryl)Al(alkyl) $\cdot \mathrm{Et}_{2} \mathrm{O}$, although the compounds exist as four different species [heteroaryl ${ }_{\mathrm{x}}(\text { alkyl })_{3-\mathrm{x}} \cdot \mathrm{Et}_{2} \mathrm{O}$, with $\mathrm{x}=0-3$ ] in solution. A combination of $1 \mathrm{~mol} \%$ palladium(II) acetate and $2 \mathrm{~mol} \%$ tri(o-tolyl)phosphine proved to be optimal for the crosscoupling of diethylpyridin-2-yl- and diethylpyridin-3-ylalane etherates $\mathbf{1 2 2}$ with a range of substituted benzyl chlorides 10a,e-m and benzyl bromide (13a) in good to excellent yields (Scheme 31).

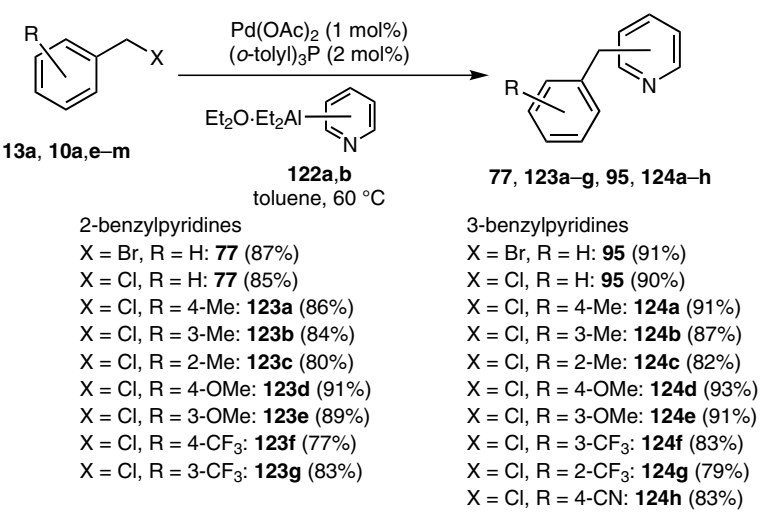

Scheme 31

\subsection{Organoboron Reagents - Suzuki-Miyaura Reaction}

In 2006, Molander and Elia disclosed the use of potassium (hetero)aryltrifluoroborates in combination with benzyl halides for the synthesis of diphenylmethanes using $\mathrm{PdCl}_{2}(\mathrm{dppf}) \cdot \mathrm{CH}_{2} \mathrm{Cl}_{2}$ as pre-catalyst. ${ }^{35}$ An example of the synthesis of a benzylpyridine is the coupling of benzyl bromide (13a) with potassium pyridin-3-yltrifluoroborate (125) in a mixture of cyclopentyl methyl ether (CPME) and water (Scheme 32). In this fashion, 3-benzylpyridine (95) was obtained in 67\% isolated yield.

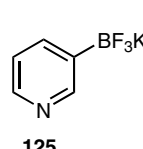

125

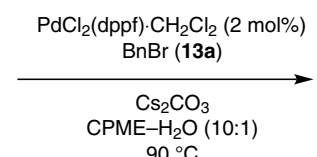

$90^{\circ} \mathrm{C}$

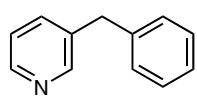

$67 \%$
Scheme 32

One year later, Kuwano and Yu reported a palladium-catalyzed decarboxylative Suzuki-Miyaura reaction of benzyl carbonates with heteroarylboronic acids. ${ }^{36} \mathrm{~A}$ small set of functionalized benzylcarbonates $\mathbf{1 2 6}$ was, for instance, coupled with pyridin-3-yl- and pyridin-4-ylboronic acids (127 and 128) in the presence of a catalytic amount of allylpalladium chloride dimer with 1,5-bis(diphenylphosphino)pentane (dpppent) as the ligand, thereby providing the corresponding 3- and 4-benzylpyridines in good to excellent yields (Scheme 33).

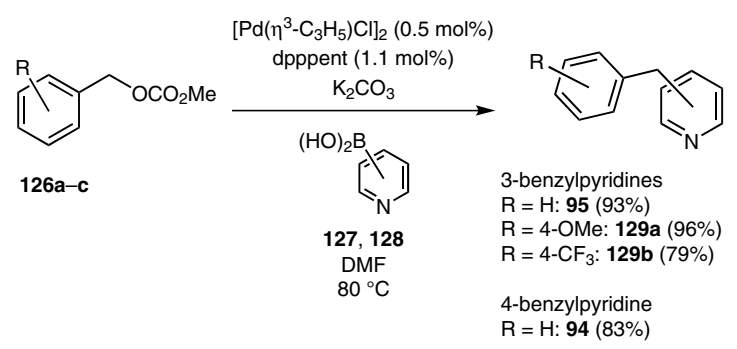

Scheme 33

4

\section{Reaction of (Di)azinylmethyl Halides with Aryl Organometallic Reagents}

\subsection{Organoboron Reagents - Suzuki-Miyaura Reaction}

In 2002, Nájera and Botella reported the use of oximederived palladacycles for Suzuki-Miyaura cross-coupling reactions in acetone-water mixtures. ${ }^{37} \mathrm{~A}$ range of chloro(methyl)- and bromo(methyl)(hetero)arenes were coupled with aromatic and aliphatic boronic acids in the presence of a catalytic amount of the palladacycle. In one example, 2-chloro-5-(chloromethyl)pyridine (130) reacted with phenylboronic acid (132a), with only $0.05 \mathrm{~mol} \%$ of palladacycle 131, to provide 5-benzyl-2-chloropyridine (133) in 40\% isolated yield (Scheme 34). 


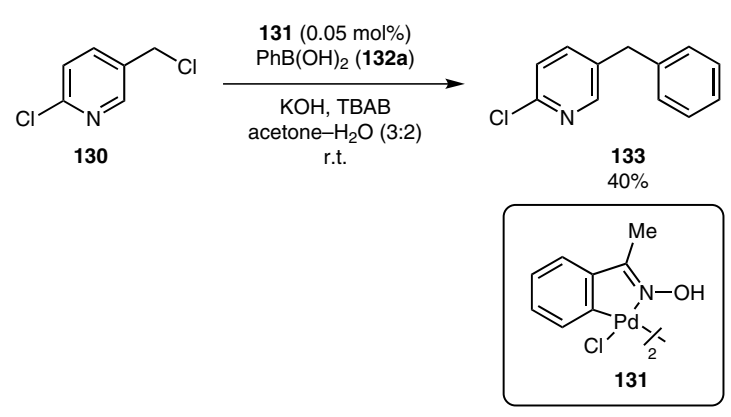

Scheme 34

More recently, in 2013, Tudge and Schmink published a paper on the use of a palladium aminobiphenyl pre-catalyst ${ }^{38} 136$ for the Suzuki-Miyaura cross-coupling of arylboronic acids with chloromethylpyridines and chloromethylazoles (not shown). ${ }^{39}$ For example, a series of functionalized 2- and 3-chloromethylpyridines 134 and $\mathbf{1 3 5}$ were coupled with different arylboronic acids $\mathbf{1 3 2}$ in moderate to good yields (Scheme 35).

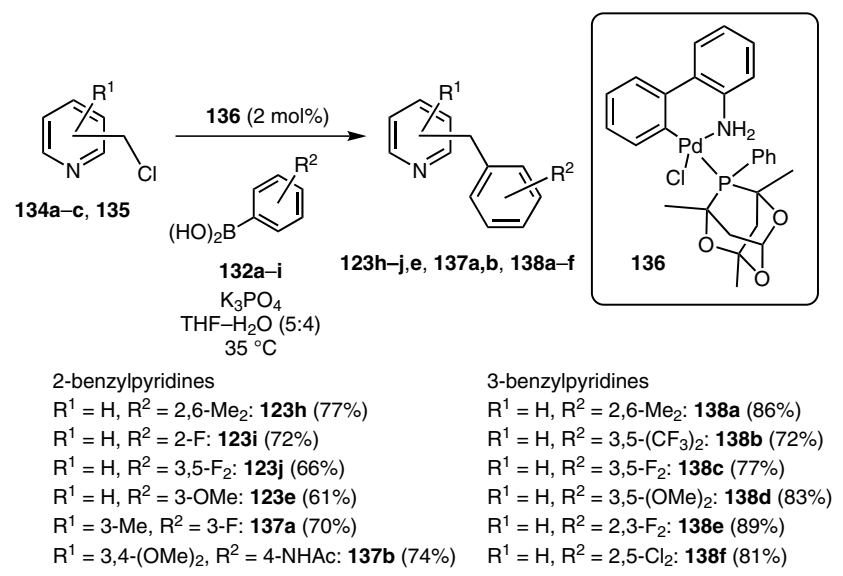

Scheme 35

\section{Reaction of Methyl(di)azine Reagents with Aryl Halides}

This section, covering the reaction of methyl(di)azines with aryl (pseudo)halides, is divided into three parts. In cases where the pre-activated methyl(di)azines are isolated, they are considered under the category of pre-activation. On the other hand, where the pre-activation takes place in situ, without intermediate isolation, this is treated as in situ pre-activation. Finally, where the methyl(di)azines are arylated as such, they are labeled as direct arylation.

\subsection{Pre-activation of Methyl(di)azines}

The first publication on the use of methyl(di)azines as reagents for the synthesis of aryl(di)azinylmethanes appeared in 2007. In it, Oshima reported the palladiumcatalyzed pyridin-2-ylmethyl transfer from 2-(pyridin-2yl)ethanol derivatives to organic halides by chelation- assisted cleavage of unstrained $\mathrm{C}_{\mathrm{sp} 3}-\mathrm{C}_{\mathrm{sp} 3}$ bonds. ${ }^{40}$ 2-Methylpyridine (139) was first activated by being transformed into 2,4-dimethyl-3-(pyridin-2-ylmethyl)pentan-3-ol (140a) in $85 \%$ yield. Then 140a was subjected to reaction with a series of substituted (hetero)aryl halides, in the presence of $5 \mathrm{~mol} \%$ of palladium(II) trifluoroacetate, 10 $\mathrm{mol} \%$ tricyclohexylphosphine and 1.2 equivalents of cesium carbonate in refluxing $o$-xylene (Scheme 36). The resulting (aryl)(di)azinylmethanes were obtained in good to excellent yields.
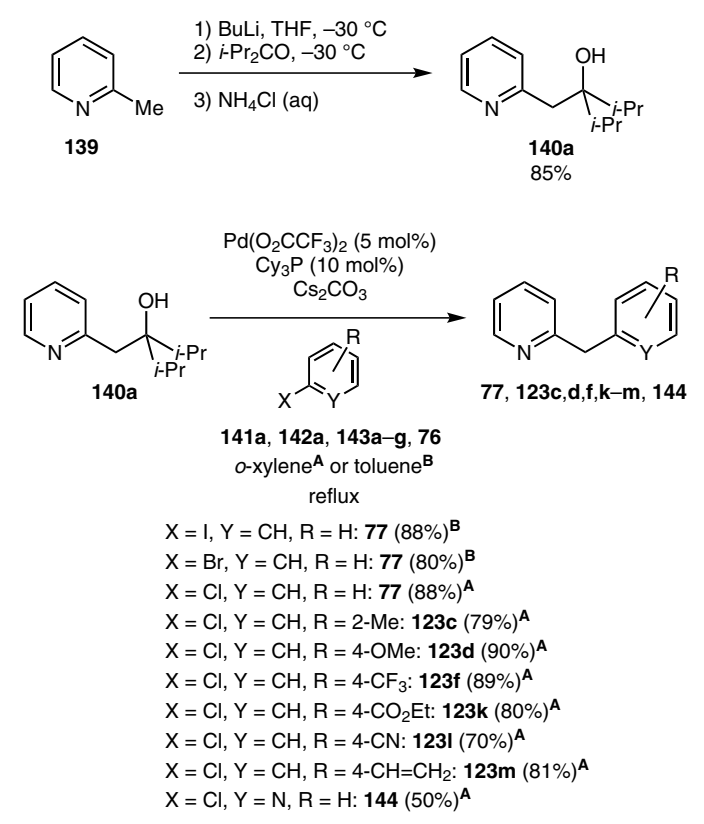

Scheme 36

During the investigation of the reaction scope, it became apparent that the presence of the $\alpha$-nitrogen was crucial for the cross-coupling to take place. The use of 2,4-dimethyl-3-(benzyl)pentan-3-ol (140b) and 2,4-dimethyl-3(pyridin-4-ylmethyl)pentan-3-ol (140c) resulted only in the recovery of starting alcohols, while other $\alpha$-nitrogencontaining substrates like 2,4-dimethyl-3-(6-methylpyridin-2-ylmethyl)pentan-3-ol (140d), 2,4-dimethyl-(6chloropyridin-2-ylmethyl)pentan-3-ol (140e), and 2,4-dimethyl-3-(pyrazinylmethyl)pentan-3-ol (140f) underwent the reaction readily, providing the corresponding benzyl(di)azines in good to excellent yields (Scheme 37).

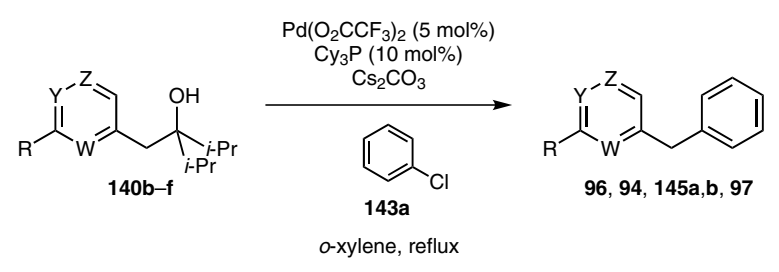

$$
\begin{aligned}
& W=Y=Z=C H, R=H: \mathbf{9 6}(0 \%) \\
& W=Z=C H, Y=N, R=H: \mathbf{9 4}(0 \%) \\
& W=N, Y=Z=C H, R=M e: 145 a(93 \%) \\
& W=N, Y=Z=C H, R=C l: 145 b(62 \%) \\
& W=Z=N, Y=C H, R=H: \mathbf{9 7}(84 \%)
\end{aligned}
$$

Scheme 37 
Based on these results, a mechanistic pathway was proposed (Scheme 38). After in situ reduction of the palladium pre-catalyst and oxidative addition to the aryl halide, ligand exchange takes place to afford the palladiumalkoxide complex 146 through coordination of the basic nitrogen to the palladium center. Coordination facilitates the cleavage of the $\mathrm{C}_{\mathrm{sp} 3}-\mathrm{C}_{\mathrm{sp} 3}$ bond, which affords palladium amide 147. After isomerization, driven by re-aromatization of the pyridine moiety, complex 148 undergoes reductive elimination, providing the desired product as well as simultaneous regeneration of the palladium catalyst.

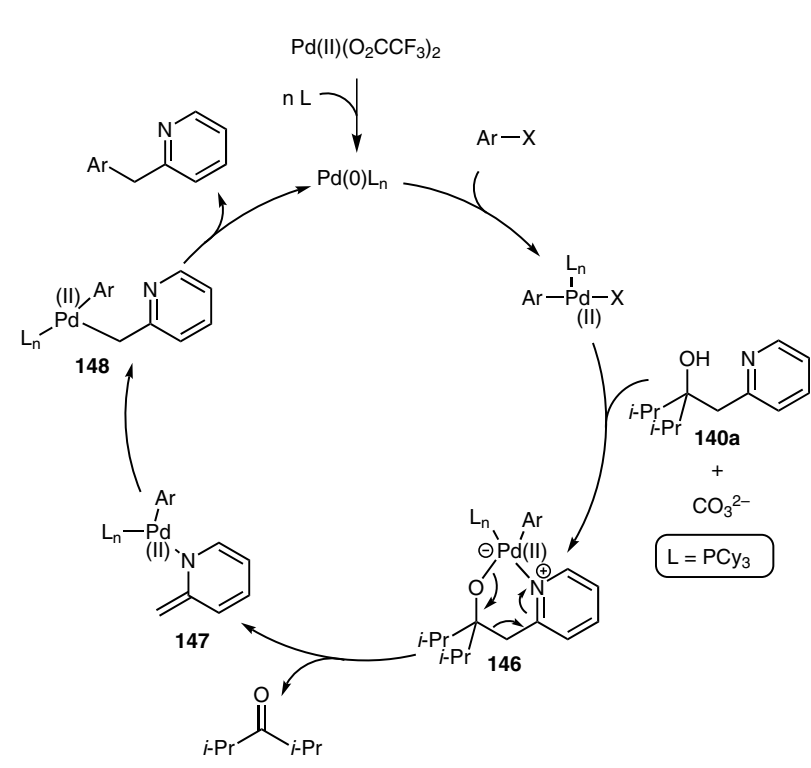

Scheme 38

In 2010, a communication by the Liu research group ${ }^{41}$ appeared, following a strategy similar to that used by Oshima. ${ }^{40}$ While the latter used di(isopropyl) ketone as a leaving group, the Liu process involved expulsion of carbon dioxide. 2-Methylpyridine (139) was first transformed into potassium 2-(pyridin-2-yl)acetate (149a) in two steps and was then coupled with a range of (hetero)aryl bromides and -triflates (Scheme 39). The resulting (aryl)(di)azinylmethanes were obtained in good to excellent yields.
The advantages associated with this coupling protocol, in comparison to the Oshima strategy, are the lower catalyst loading [0.5-2 mol\% of $\mathrm{Pd}_{2}(\mathrm{dba})_{3}$, with $1.5-6 \mathrm{~mol} \%$ of Xantphos] and the fact that no base is required in the palladium-catalyzed cross-coupling reaction. Using this procedure, a range of substituted potassium 2-(pyridin-2-yl)-, pyrazinyl- and (quinolin-2-yl)acetates as well as sodium benzoxazol-2-yl- and benzothiazol-2-ylacetates were smoothly coupled with substituted aryl bromides. The 2benzylpyridine and benzylpyrazine products were obtained in good to excellent yields (Scheme 40).

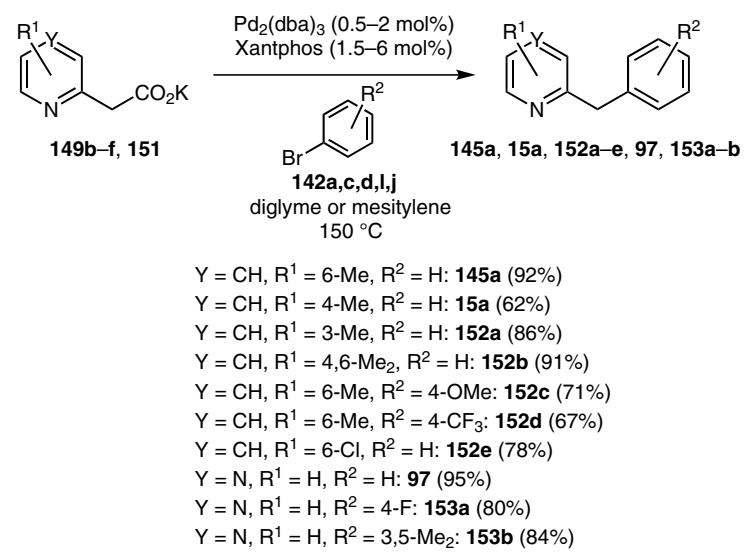

Scheme 40

In 2008, Fagnou and co-workers communicated on a siteselective $\mathrm{sp}^{2}$ and/or benzylic $\mathrm{sp}^{3}$ palladium-catalyzed arylation of 2 -methyl(di)azine $N$-oxides. ${ }^{42}$ During this research, the authors noticed that lower yields were encountered with substrates bearing methyl substituents adjacent to the $N$-oxide moiety. By careful choice of the conditions $\left[5 \mathrm{~mol} \% \mathrm{Pd}(\mathrm{OAc})_{2}, 5 \mathrm{~mol} \%(t-\mathrm{Bu})_{3} \mathrm{P}, 1.05\right.$ equiv $\mathrm{K}_{2} \mathrm{CO}_{3}$, toluene, reflux], $\mathrm{sp}^{3}$ arylation could be avoided and only (hetero)arylated 2-picoline $N$-oxides were obtained. The authors envisioned that it also should be possible to reverse the $\mathrm{sp}^{2}-\mathrm{sp}^{3}$ selectivity by re-optimizing the catalyst/ligand system and the base. Indeed, the use of $2.5 \mathrm{~mol}^{\circ} \mathrm{Pd}_{2}(\mathrm{dba})_{3}, 5 \mathrm{~mol} \%$ XPhos and 3 equivalents of sodium tert-butoxide in refluxing toluene under microwave heating gave exclusively $\mathrm{sp}^{3}$-arylation.

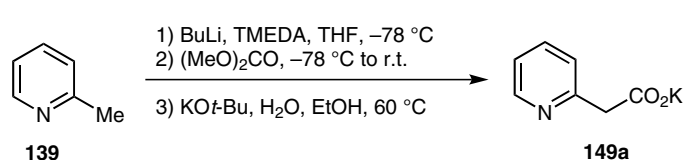

$\mathrm{X}=\mathrm{Br}, \mathrm{Y}=\mathrm{CH}, \mathrm{R}=\mathrm{H}: \mathbf{7 7}(96 \%)$ $\mathrm{X}=\mathrm{OTf}, \mathrm{Y}=\mathrm{CH}, \mathrm{R}=\mathrm{H}: \mathbf{7 7}(84 \%)$ $X=\mathrm{Br}, \mathrm{Y}=\mathrm{CH}, \mathrm{R}=4-\mathrm{Me}: \mathbf{1 2 3} \mathrm{a}(93 \%)$ $\mathrm{X}=\mathrm{OTf}, \mathrm{Y}=\mathrm{CH}, \mathrm{R}=4-\mathrm{Me}:$ 123a $(72 \%)$ $X=\mathrm{Br}, Y=\mathrm{CH}, \mathrm{R}=4-\mathrm{OMe}: 123 \mathrm{~d}(73 \%)$ $X=O T f, Y=C H, R=4-O M e: 123 d(76 \%)$ $X=\mathrm{OT}, Y=\mathrm{CH}, \mathrm{R}=4-\mathrm{OMe}: 123 \mathrm{~d}(76 \%)$ $X=\mathrm{Br}, \mathrm{Y}=\mathrm{CH}, \mathrm{R}=4-\mathrm{CF}_{3}: \mathbf{1 2 3 f}(79 \%)$
$\mathrm{X}=\mathrm{Cl}, \mathrm{Y}=\mathrm{CH}, \mathrm{R}=4-\mathrm{CF}_{3}: \mathbf{1 2 3 f}(66 \%)$
149

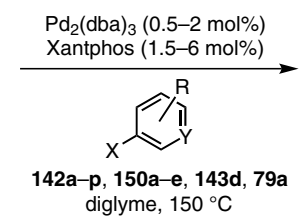

$\mathrm{X}=\mathrm{Br}, \mathrm{Y}=\mathrm{CH}, \mathrm{R}=3-\mathrm{CF}_{3}: \mathbf{1 2 3} \mathbf{g}(98 \%)$ $\mathrm{X}=\mathrm{Br}, \mathrm{Y}=\mathrm{CH}, \mathrm{R}=4$-SMe: $123 \mathrm{n}(89 \%)$ $\mathrm{X}=\mathrm{Br}, \mathrm{Y}=\mathrm{CH}, \mathrm{R}=2$-OMe: $1230(81 \%)$ $\mathrm{X}=\mathrm{Br}, \mathrm{Y}=\mathrm{CH}, \mathrm{R}=4$-OTs: $123 \mathrm{p}(72 \%)$ $\mathrm{X}=\mathrm{Br}, \mathrm{Y}=\mathrm{CH}, \mathrm{R}=4-\mathrm{OCF}_{3}: 123 \mathrm{q}(92 \%)$ $\mathrm{X}=\mathrm{Br}, \mathrm{Y}=\mathrm{CH}, \mathrm{R}=3,5-\mathrm{Me}_{2}: 123 \mathrm{r}(95 \%)$ $X=O T f, Y=C H, R=3,5-M_{2}: 123 r(87 \%)$ $\mathrm{X}=\mathrm{Br}, \mathrm{Y}=\mathrm{CH}, \mathrm{R}=2-\mathrm{F}-5-\mathrm{Me}: 123 \mathrm{~s}(82 \%)$

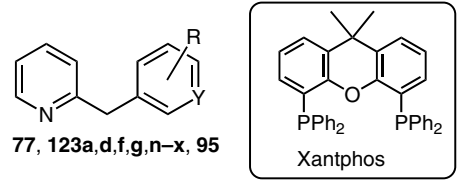

$\mathrm{X}=\mathrm{Br}, \mathrm{Y}=\mathrm{CH}, \mathrm{R}=4-\mathrm{F}: \mathbf{1 2 3 t}(84 \%)$ $\mathrm{X}=\mathrm{Br}, \mathrm{Y}=\mathrm{CH}, \mathrm{R}=4-\mathrm{Cl}: \mathbf{1 2 3 u}(70 \%)$ $\mathrm{X}=\mathrm{OTf}, \mathrm{Y}=\mathrm{CH}, \mathrm{R}=4-\mathrm{Cl}: \mathbf{1 2 3 u}(78 \%)$ $\mathrm{X}=\mathrm{Br}, \mathrm{Y}=\mathrm{CH}, \mathrm{R}=2-\mathrm{Br}: 123 \mathrm{v}(82 \%)$ $\mathrm{X}=\mathrm{Br}, \mathrm{Y}=\mathrm{CH}, \mathrm{R}=4-\mathrm{CO}_{2} \mathrm{Me}: \mathbf{1 2 3 w}(73 \%)$ $\mathrm{X}=\mathrm{Br}, \mathrm{Y}=\mathrm{CH}, \mathrm{R}=3-\mathrm{CN}: 123 \mathbf{x}(86 \%)$ $\mathrm{X}=\mathrm{Br}, \mathrm{Y}=\mathrm{N}, \mathrm{R}=\mathrm{H} \cdot \mathrm{95}(84 \%)$

Scheme 39 
Under these conditions, a set of substituted aryl halides 142 were coupled with 2-methylpyridine $N$-oxide (154) and 2,3-dimethylpyrazine $N$-oxide (155). The corresponding 2-benzyl(di)azine $N$-oxides (156a-e, 157) were obtained in good yields (Scheme 41). The 2-benzyl(di)azine $\mathrm{N}$-oxides could be deoxygenated easily, as exemplified by the reduction of 156a and $\mathbf{1 5 7}$ (Scheme 42).

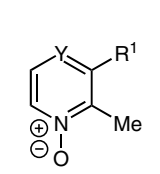

154,155

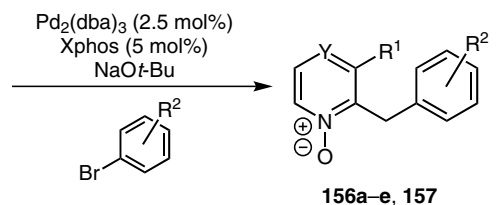

142b,c,I,j,q toluene, $110^{\circ} \mathrm{C}(\mu \mathrm{w})$

$Y=\mathrm{CH}, \mathrm{R}^{1}=\mathrm{H}, \mathrm{R}^{2}=4-\mathrm{Me}: \mathbf{1 5 6 a}(89 \%)$

$\mathrm{Y}=\mathrm{CH}, \mathrm{R}^{1}=\mathrm{H}, \mathrm{R}^{2}=4-\mathrm{OMe}: 156 \mathrm{~b}(72 \%)$

$Y=\mathrm{CH}, \mathrm{R}^{1}=\mathrm{H}, \mathrm{R}^{2}=4-\mathrm{F}:$ 156c $(72 \%)$

$Y=C H, R^{1}=H, R^{2}=3,5-M_{2}: 156 d(64 \%)$

$\mathrm{Y}=\mathrm{CH}, \mathrm{R}^{1}=\mathrm{H}, \mathrm{R}^{2}=3,5-(\mathrm{OMe})_{2}: 156 \mathrm{e}(70 \%)$

$\mathrm{Y}=\mathrm{N}, \mathrm{R}^{1}=\mathrm{Me}, \mathrm{R}^{2}=4-\mathrm{Me}: 157(79 \%)$

\section{Scheme 41}

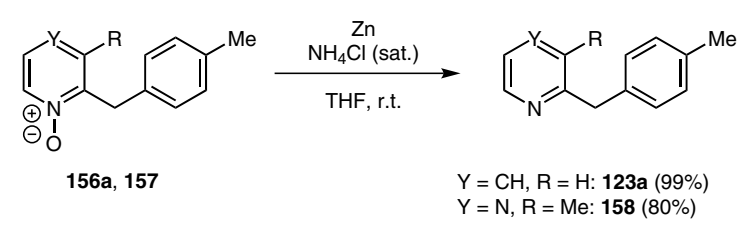

Scheme 42

One year later, the same authors published a follow-up paper on the site-selective $\mathrm{sp}^{3}$-arylation. ${ }^{43}$ It was found that besides aryl bromides, aryl chlorides and iodides could also be used as coupling partners. While electron-donating groups (e.g., Me, OMe) on the aryl halide were well tolerated, the presence of electron-withdrawing groups (e.g., $\mathrm{CN}, \mathrm{CO}_{2} \mathrm{Et}, \mathrm{NO}_{2}, \mathrm{COPh}$ ) on the aryl halide led to only traces of the benzylated products. Methyl substituents on the picoline $N$-oxide did not hamper the reaction (Scheme 43).

Notably, in the case of $\mathbf{1 5 9}$, where the methyl substituents are in positions $\alpha$ and $\gamma$ to the nitrogen, the reaction proceeds exclusively on the C-2 methyl group, suggesting the influence of the $N$-oxide moiety on the regioselectivity (Scheme 43). In a control experiment, where 4-picoline $N$ oxide (163) was subjected to the optimized conditions, only $\mathrm{sp}^{2}$-arylated product 164a was observed (Scheme 44).

Based on these results and on the observation that the choice of base $\left(\mathrm{K}_{2} \mathrm{CO}_{3}\right.$ vs. $\mathrm{NaO}$ - $\left.\mathrm{Bu}\right)$ has a great influence on the site-selectivity of the reaction, the authors proposed a mechanism (Scheme 45). The active palladium(0) catalyst oxidatively inserts into the aryl halide bond, providing intermediate 165. The next step, palladation of the

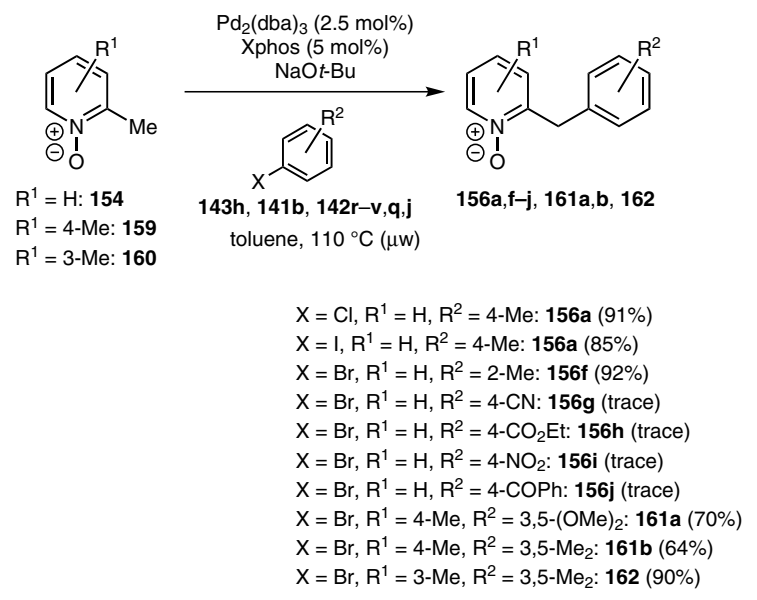

Scheme 43

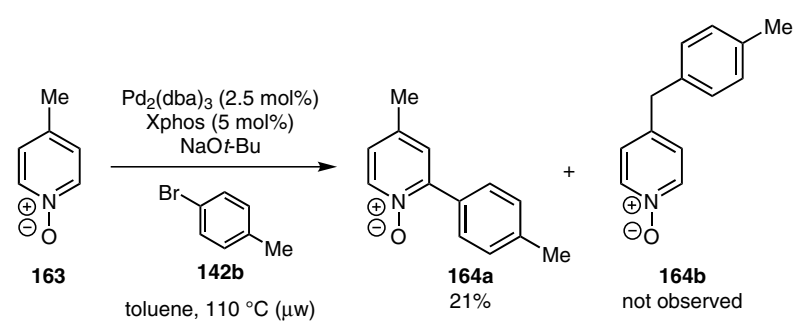

Scheme 44

$\mathrm{N}$-oxide, determines the site-selectivity and is base-dependant. With sodium tert-butoxide, the stronger base, the most acidic $\mathrm{sp}^{3}$ 2-methyl position is deprotonated to yield palladacycle 166. Potassium carbonate, on the other hand, is not strong enough to deprotonate the 2-methyl position, but it does allow a six-membered transition state (concerted metalation-deprotonation pathway) to activate the $\mathrm{sp}^{2}$ position, which gives rise to complex 167. Both intermediates 166 and 167 undergo reductive elimination to form products $\mathbf{A}$ and $\mathbf{B}$, respectively, as well as the palladium( $(0)$ catalyst.

During the same period, a paper by the Charette research group was published on the $\mathrm{sp}^{3}$ arylation of $N$-imino-2methylpyridinium ylides. ${ }^{44}$ In the course of their research on the $\mathrm{sp}^{2}$ arylation of $N$-iminopyridinium ylides, the authors had made the same observation as Fagnou. ${ }^{42}$ When a methyl group adjacent to the quaternized nitrogen was present, the yields of $\mathrm{sp}^{2}$ arylation dropped and those of $\mathrm{sp}^{3}$ arylation increased. The optimal conditions for the $\mathrm{sp}^{3}$ arylation were found to be $5 \mathrm{~mol} \%$ palladium(II) acetate, $12 \mathrm{~mol} \%$ DavePhos and 3 equivalents of cesium carbonate in $\mathrm{N}, \mathrm{N}$-dimethylformamide at $70{ }^{\circ} \mathrm{C}$. The use of a carbonate base is in contrast to Fagnou's work, where a stronger base was needed for $\mathrm{sp}^{3}$ arylation and potassium carbonate promoted $\mathrm{sp}^{2}$ arylation. A series of (substituted) $N$-imino-2-methylpyridinium ylides $168 \mathbf{a}-\mathbf{c}$ were coupled in this way with functionalized aryl halides 143, giving rise to the corresponding benzylated products in moderate to excellent yields (Scheme 46). 


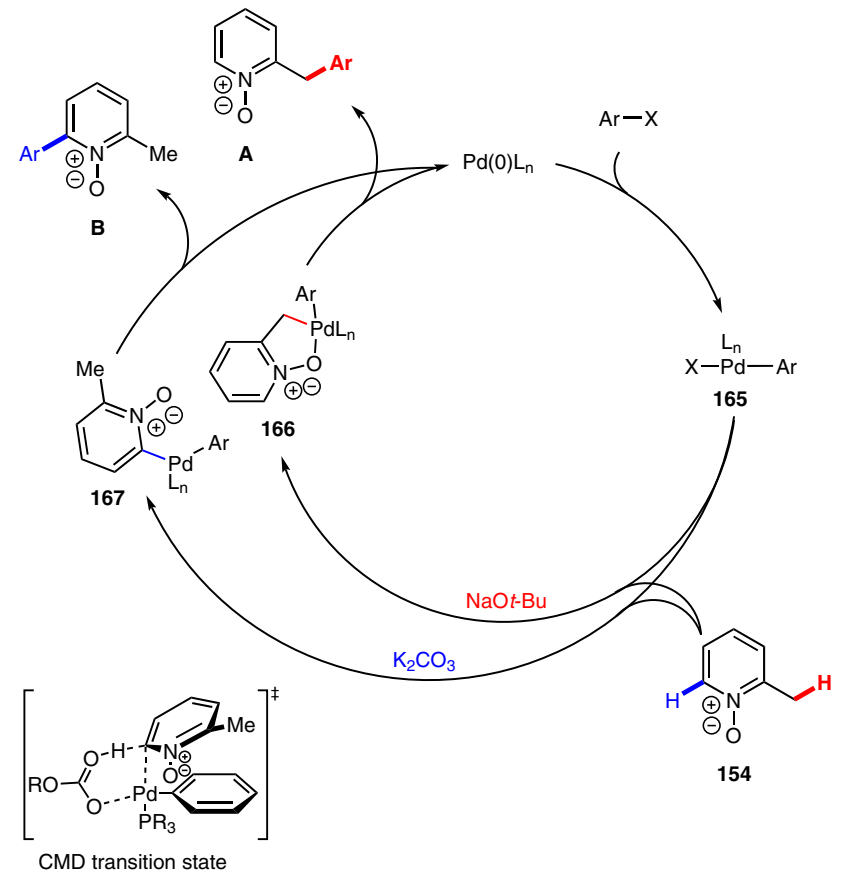

Scheme 45

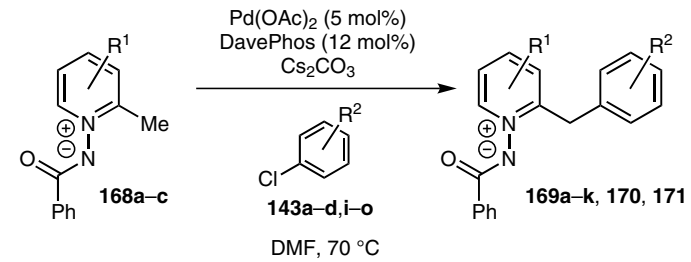

$R^{1}=H, R^{2}=H: 169 a(86 \%)$

$R^{1}=H, R^{2}=2-M e: 169 b(93 \%)$

$\mathrm{R}^{1}=\mathrm{H}, \mathrm{R}^{2}=4-\mathrm{OMe}: 169 \mathrm{c}(69 \%)$

$\mathrm{R}^{1}=\mathrm{H}, \mathrm{R}^{2}=4-\mathrm{CF}_{3}: 169 \mathrm{~d}(64 \%)$

$R^{1}=H, R^{2}=4-M e: 169 e(72 \%)$

$\mathrm{R}^{1}=\mathrm{H}, \mathrm{R}^{2}=4-\mathrm{NHBoc}: \mathbf{1 6 9 f}(48 \%)$

$R^{1}=H, R^{2}=3-M e: 169 g(76 \%)$

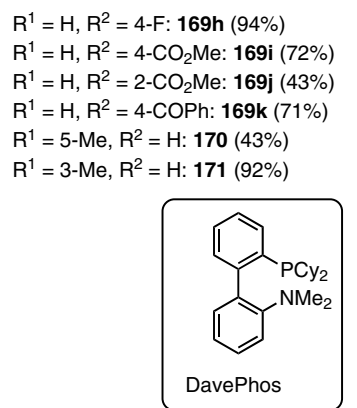

Scheme 46

Reduction of the $N$-imino-2-benzylpyridinium ylide was not shown in that report. The authors only mentioned the reduction of an $\mathrm{N}$-imino-2-arylpyridinium ylide in their previous paper on $\mathrm{sp}^{2}$ arylation. ${ }^{45}$ Quantitative methylation of the imino nitrogen of $\mathbf{1 7 2}$ with iodomethane, followed by treatment of the obtained salt 173 with zinc dust in acetic acid, with tris(trimethylsilyl)silane and azobisisobutyronitrile, or with ammonium formate and platinum on carbon, afforded the desired product $\mathbf{1 7 4}$ in good yield (Scheme 47).

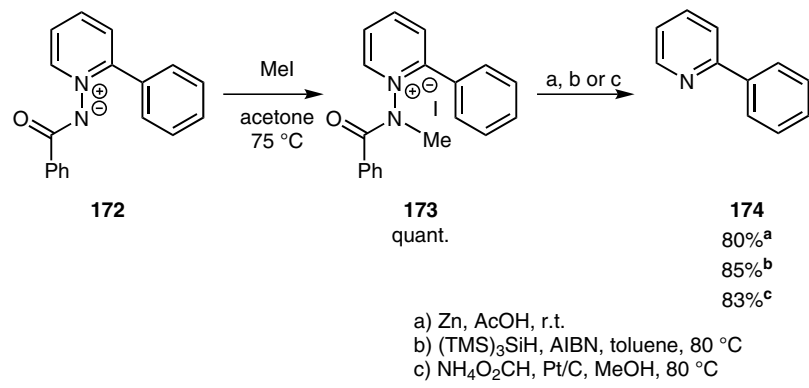

Scheme 47

\subsection{In Situ Pre-activation of Methyl(di)azines}

In 2011, Knochel and co-workers reported the Lewis acid promoted benzylic cross-couplings of in situ activated methylpyridines with aryl bromides. ${ }^{46}$ The authors stated that one of the problems regarding the direct arylation of 2-picoline (139) may be the structure of the oxidative addition complex: chelation of the heterocyclic $\mathrm{sp}^{2}$ nitrogen to the electrophilic palladium(II) center might hamper the reductive elimination step. It was anticipated that the presence of a Lewis acid complexing the nitrogen would lead to a faster reductive elimination, providing the crosscoupled products.

For this purpose, 2-picoline (139) was first zincated with two equivalents of $\mathrm{TMPZnCl} \cdot \mathrm{LiCl}$, a base bearing a Lewis acidic metal center which was already known to be compatible with other strong Lewis acids like magnesium chloride and boron trifluoride diethyl etherate, giving rise to pyridin-2-ylmethylzinc chloride $(\mathbf{1 7 6 a} ; \mathrm{X}=\mathrm{N}, \mathrm{Y}=$ $\mathrm{CH})$. This organozinc compound was then cross-coupled with a series of functionalized aryl bromides 142 using 2 mol\% palladium(II) acetate and $2-4 \mathrm{~mol} \% \mathrm{SPhos}$ in tetrahydrofuran at $50{ }^{\circ} \mathrm{C}$. While the aryl bromides bearing electron-donating substituents $(\mathrm{R}=\mathrm{OMe}, \mathrm{F}, \mathrm{Cl})$ were coupled in good to excellent yields, those bearing electron-withdrawing substituents $\left(\mathrm{CN}, \mathrm{CO}_{2} \mathrm{Et}\right)$ gave unsatisfactory yields of the functionalized 2-benzylpyridines $\mathbf{1 2 3}$ (Scheme 48). The use of $10 \mathrm{~mol} \%$ of the stronger Lewis acid scandium(III) triflate gave a more efficient reaction, presumably due to the aforementioned acceleration of the reductive elimination. In this fashion, aryl bromides 142s,t bearing electron-withdrawing substituents $(\mathbf{1 4 2 s , \mathbf { t } )}$ were also coupled in good to excellent yields (Scheme 48).

While none of the previous methods based on the arylation of pre-activated methyl(di)azines were able to perform a cross-coupling $\gamma$ to the heterocyclic nitrogen, the present procedure does allow the use of 4-picoline (175) as a substrate. Under the optimized conditions, $\mathbf{1 7 5}$ could be efficiently zincated by 1.5 equivalents of $\mathrm{TMPZnCl} \cdot \mathrm{LiCl}$, followed by cross-coupling with a range of substituted aryl bromides 142 (Scheme 48). In the case of electrondeficient aryl bromides, the use of scandium(III) triflate again had a beneficial effect on the isolated yield. 


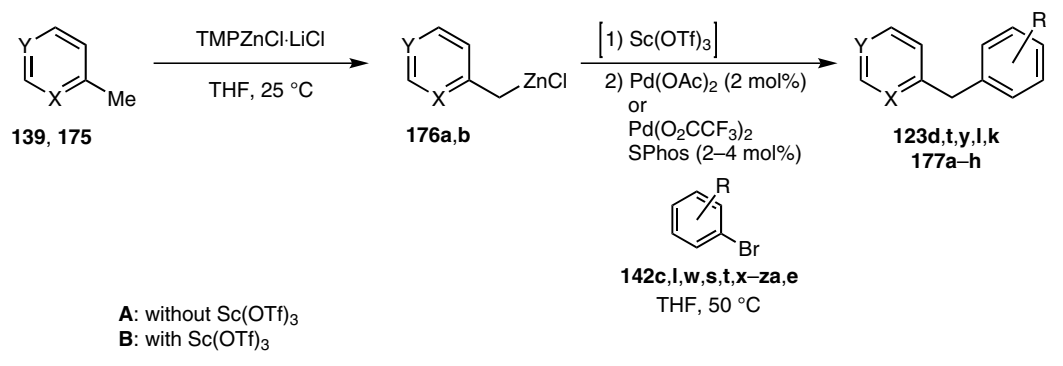

2-benzylpyridines

$\mathrm{X}=\mathrm{N}, \mathrm{Y}=\mathrm{CH}, \mathrm{R}=4$-OMe: $\mathbf{1 2 3 d}(95 \%)$

$\mathrm{X}=\mathrm{N}, \mathrm{Y}=\mathrm{CH}, \mathrm{R}=4-\mathrm{F}: \mathbf{1 2 3 t}(78 \%)$

$\mathrm{X}=\mathrm{N}, \mathrm{Y}=\mathrm{CH}, \mathrm{R}=3-\mathrm{Cl}: \mathbf{1 2 3 y}(66 \%)$

$\mathrm{X}=\mathrm{N}, \mathrm{Y}=\mathrm{CH}, \mathrm{R}=4-\mathrm{CN}: \mathbf{1 2 3 I}(0 \%)^{\mathbf{A}}(87 \%)^{\mathbf{B}}$

$\mathrm{X}=\mathrm{N}, \mathrm{Y}=\mathrm{CH}, \mathrm{R}=4-\mathrm{CO}_{2} \mathrm{Et}: 123 \mathrm{k}(31 \%)^{\mathbf{A}}(85 \%)^{\mathbf{B}}$

4-benzylpyridines

$\mathrm{X}=\mathrm{CH}, \mathrm{Y}=\mathrm{N}, \mathrm{R}=4$-OMe: $177 \mathrm{a}(98 \%)$

$\mathrm{X}=\mathrm{CH}, \mathrm{Y}=\mathrm{N}, \mathrm{R}=4-\mathrm{OH}: \mathbf{1 7 7 b}(84 \%)$

$\mathrm{X}=\mathrm{CH}, \mathrm{Y}=\mathrm{N}, \mathrm{R}=4$-OPiv: $177 \mathrm{c}(81 \%)$

$\mathrm{X}=\mathrm{CH}, \mathrm{Y}=\mathrm{N}, \mathrm{R}=4-\mathrm{NMe}_{2}: 177 \mathrm{~d}(70 \%)$

$\mathrm{X}=\mathrm{CH}, \mathrm{Y}=\mathrm{N}, \mathrm{R}=3-\mathrm{Me}: \mathbf{1 7 7 e}(82 \%)$

$\mathrm{X}=\mathrm{CH}, \mathrm{Y}=\mathrm{N}, \mathrm{R}=4-\mathrm{CO}_{2} \mathrm{Et}: \mathbf{1 7 7 f}(41 \%)^{\mathbf{A}}(78 \%)^{\mathbf{B}}$

$\mathrm{X}=\mathrm{CH}, \mathrm{Y}=\mathrm{N}, \mathrm{R}=4-\mathrm{CN}: \mathbf{1 7 7 g}(0 \%)^{\mathbf{A}}(75 \%)^{\mathbf{B}}$

$\mathrm{X}=\mathrm{CH}, \mathrm{Y}=\mathrm{N}, \mathrm{R}=3-\mathrm{CF}_{3}: 177 \mathrm{~h}(51 \%)^{\mathbf{A}}(78 \%)^{\mathbf{B}}$

Scheme 48

The authors subsequently studied the regioselective arylation of lutidines. In the case of 2,3-lutidine (178a) and 3,4lutidine $(\mathbf{1 7 8 b})$, zincation with $\mathrm{TMPZnCl} \cdot \mathrm{LiCl}$ occured exclusively at the 2- and 4-position, respectively, leading to the corresponding disubstituted pyridines $180 \mathbf{a}-\mathbf{d}$ and 181 after palladium-catalyzed arylation with functionalized aryl bromides 142 (Scheme 49). With 2,4-lutidine (178c), the zincation produced a 2:1 mixture of regioisomers. The addition of 1.1 equivalents of boron trifluoride diethyl etherate prior to that of the zincating reagent directs the zincation only at the 4-position, since the complexation of boron trifluoride diethyl etherate at the $\mathrm{sp}^{2}$ nitrogen hampers the metalation at the 2-position for steric reasons. The resulting (2-methylpyridin-4-yl)methylzinc chloride (179c) was then cross-coupled with a series of functionalized aryl bromides 142, chlorides 143 and triflate 150c, providing the 4-benzyl-2-methylpyridines 182a-h regioselectively in good to excellent yields (Scheme 49).

\subsection{Direct Arylation of Methyl(di)azines}

The first direct arylation (without pre-activation of the substrate) of methyl(di)azines was established by Morris and Burton in 2010. ${ }^{47}$ During their ongoing research on naphthyridines, the authors sought to prepare 2-benzyl1,8-naphthyridines at a late stage in the synthesis. After promising exploratory studies, the authors performed an optimization of the coupling conditions. It was found that $2.5-5 \mathrm{~mol} \%$ of the Fairlamb pre-catalyst $\mathrm{Pd}\left[3,5,3^{\prime}, 5^{\prime}-\right.$ $\left.(\mathrm{MeO})_{4}-\mathrm{dba}\right]_{2},{ }^{48} 2.5-5 \mathrm{~mol} \%$ Xantphos and 2 equivalents of cesium carbonate in dioxane at $100{ }^{\circ} \mathrm{C}$ gave the best results with regard to reactivity and selectivity between mono- and bisarylation. A range of (substituted) 2-methyl-1,8-naphthyridines were coupled in this way, with (functionalized) aryl iodides, bromides and triflates, while aryl chlorides gave no reaction. In another phase, it was tested whether methyl(di)azines would undergo the same reaction. While 4-methylpyrimidine (183) was coupled efficiently with 2-bromotoluene (142r) in $81 \%$ isolated yield, 2-methylpyrazine (184) and methylpyridine (139) gave none of the desired benzylated product (Scheme 50). Introduction of an electron-withdrawing group at the 5position of the 2-methylpyridine allowed the reaction to proceed well, providing the substituted 2-benzylpyridines 188a,b in good yields. Apparently, the acidity of the methyl $\mathrm{C}-\mathrm{H}$ is crucial for the reaction to take place.
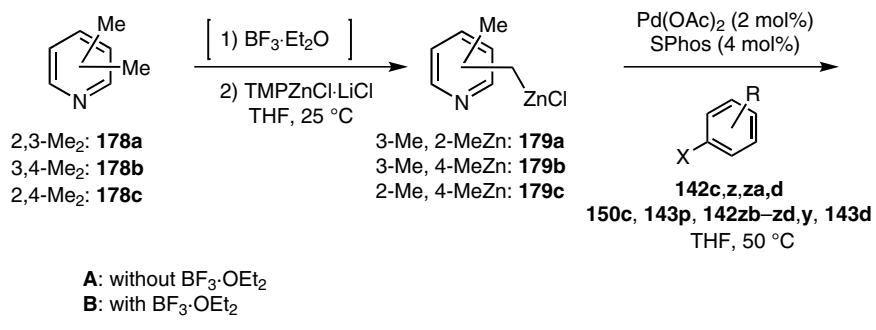

THF, $50^{\circ} \mathrm{C}$

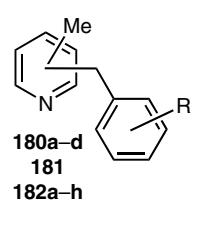

4-benzyl-2-methylpyridines $\mathrm{X}=\mathrm{Br}, \mathrm{R}=4-\mathrm{OMe}: \mathbf{1 8 2 a}(92 \%)^{\mathrm{B}}$ $X=$ OTf, R $=4$-OMe: $182 b(98 \%)^{\mathrm{B}}$ $\mathrm{X}=\mathrm{Cl}, \mathrm{R}=3$-OMe: $182 \mathrm{c}(86 \%)^{\mathrm{B}}$ $\mathrm{X}=\mathrm{Br}, \mathrm{R}=2-\mathrm{OMe}: \mathbf{1 8 2 d}(92 \%)^{B}$ $\mathrm{X}=\mathrm{Br}, \mathrm{R}=4-\mathrm{CO}_{2} \mathrm{Et}: \mathbf{1 8 2 e}(82 \%)^{\mathrm{B}}$ $\mathrm{X}=\mathrm{Br}, \mathrm{R}=4-\mathrm{CN}: \mathbf{1 8 2 f}(77 \%)^{\mathrm{B}}$ $\mathrm{X}=\mathrm{Br}, \mathrm{R}=4$-OPiv: $182 \mathrm{~g}(82 \%)^{\mathrm{B}}$ $\mathrm{X}=\mathrm{Cl}, \mathrm{R}=4-\mathrm{CF}_{3}: 182 \mathrm{~h}(92 \%)^{\mathrm{B}}$

Scheme 49 


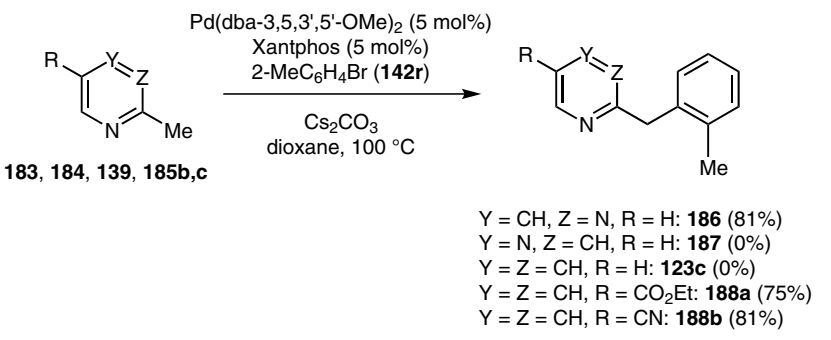

Scheme 50

One year later, $\mathrm{Li}$ and co-workers reported the palladiumcatalyzed arylation of methylbenzazoles (benzimidazole, benzoxazole and benzothiazole) and methyl(benzo)(di)azines (pyridine, pyrazine, pyrimidine, pyridazine and quinoline), ${ }^{49}$ based on the same principle as Morris. ${ }^{47}$ With a stronger base $\left(\mathrm{NaO} t\right.$ - $\mathrm{Bu}$ vs $\left.\mathrm{Cs}_{2} \mathrm{CO}_{3}\right)$ in $o$-xylene at $130{ }^{\circ} \mathrm{C}$, predominantly diarylation occured. This was later optimized to provide only diarylation, resulting in the corresponding diaryl(di)azinylmethanes. Although a stronger base principally allows for the arylation of less acidic methylenes, overarylation unfortunately becomes the major reaction.

\section{6 \\ Reaction of (Di)azine $N$-Oxides with Benzyl (Pseudo)halides}

Based on the work of the Fagnou team (vide supra), ${ }^{42}$ Mai prepared a set of benzylated (di)azine $N$-oxides by the coupling of (di)azine $N$-oxides with benzyl halides. ${ }^{50}$ During the optimization, the authors noticed that benzyl chloride (10a) as coupling partner gave a superior isolated yield $(82 \%)$ in comparison with benzyl bromide (13a, $43 \%$ ), while benzyl tosylate (190) only gave a trace amount of product (Scheme 51). The combination of 5 mol\% palladium(II) acetate, $10 \mathrm{~mol} \% \mathrm{P}(t-\mathrm{Bu})_{3} \cdot \mathrm{HBF}_{4}$ and potassium carbonate in refluxing toluene proved to be the optimal coupling conditions. In this manner, a range of (substituted) (di)azine $N$-oxides 189 were coupled with functionalized benzyl chlorides 10. The corresponding 2benzyl(di)azine $N$-oxides 156, 191 and 192 were obtained in good yields (Scheme 51). A control experiment, where the coupling conditions were applied to pyridine, gave no 2-benzylpyridine (77), proving the necessity of the activating $\mathrm{N}$-oxide moiety. The coupled products were easily deoxygenated as exemplified in Scheme 52 by the reduction of 156k into 2-benzylpyridine (77).

\section{$7 \quad$ Conclusion}

In the last decade, many efforts have been made regarding the synthesis of functionalized aryl(di)azinylmethanes via transition-metal-catalyzed cross-couplings, with the majority of them based on the Negishi reaction. A great contribution to this field was made by the Knochel group, with a number of important publications on the practical preparation of (highly) functionalized benzylzinc halides

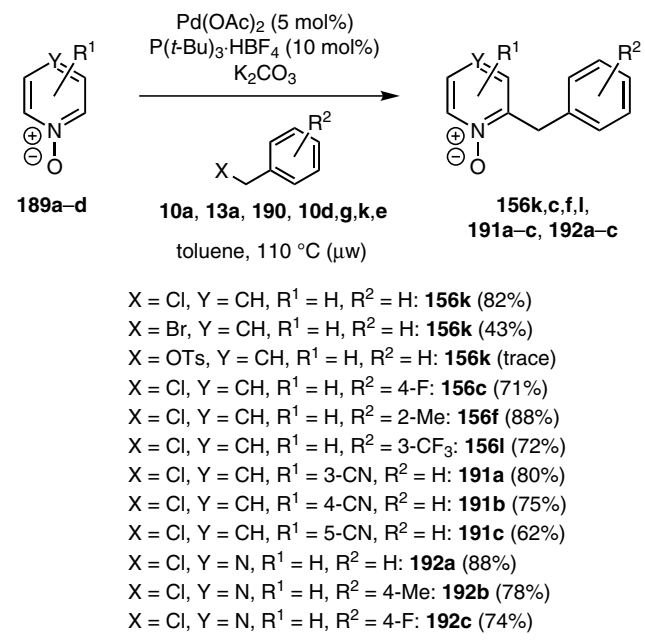

Scheme 51

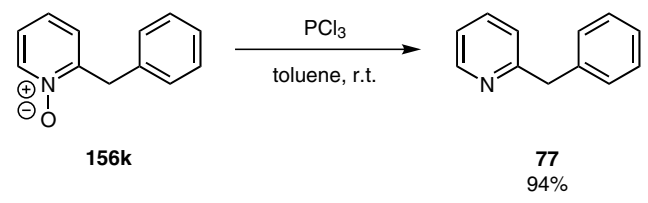

Scheme 52

as well as their further palladium- or nickel-catalyzed cross-coupling with a variety of (di)azinyl (pseudo)halides and (di)azinyl methyl thioethers. This makes the Negishi reaction attractive for library build-up. On the other hand, the Negishi reaction demands anhydrous conditions, which is not required for the more stable, less demanding organometallics based on, for example, boron and tin. However, reports on the use of the latter two metals to prepare the aryl(di)azinylmethane motif are surprisingly scarce, consequently their (general) applicability remains unfortunately unknown. It should also be noted that all transition-metal-catalyzed cross-couplings for aryl(di)azinylmethane synthesis are based on palladium or nickel catalysts, with only one exception based on copper.

The coupling of (in situ) pre-activated methyl(di)azines with aryl halides provides a more straightforward approach to the desired aryl(di)azinylmethanes. As mentioned in the introduction, a range of methyl(di)azines are easily accessible from condensation reactions or from natural feedstocks, making them valuable alternatives to their halogenated counterparts. Moreover, this approach easily allows the synthesis of bis(di)azinylmethanes, while no other transition-metal-catalyzed reactions are reported to construct these scaffolds. If one compares the different coupling strategies from (in situ) pre-activated methyl(di)azines, the procedures published by Fagnou, Charette and Mai are generally the least attractive. The substrates, $\alpha$-methyl(di)azines, have to be activated, cross-coupled and then de-activated to yield the desired 
aryl(di)azinylmethanes. On the other hand, the (di)azine $\mathrm{N}$-oxides can be deoxygenated via simultaneous (di)azine functionalization providing an extra derivatization tool which can be advantageous in specific cases. ${ }^{51}$ The procedures published by Oshima and Liu are mechanistically closely related to each other and offer good functional group tolerance, making them well-suited for the synthesis of functionalized aryl(di)azin-2-ylmethanes and bis(di)azinylmethanes, with the disadvantage that here, also, a separate activation step is required and an $\alpha$-nitrogen atom is an essential structural element. The protocol proposed by Knochel definitely has the best generality, in terms of substrate scope and availability ( $\alpha$ - and $\gamma$ - to nitrogen; use of aryl chlorides, bromides and tosylates) and functional group tolerance. Nevertheless, in situ pre-activation still requires stoichiometric metalating agents, Lewis acids and anhydrous conditions. The protocol reported by Morris is methodologically by far the most appealing as it is the only 'true' direct arylation protocol hitherto available. It is, however, not general as the substrates need a certain degree of electron deficiency for the reaction to take place, and this limits its scope significantly. Although a lot has already been achieved in this field, the authors believe that there is still room for further improvement in the direct arylation of methyl(di)azines. Extending the scope of the Morris procedure to more electron-rich methyl(di)azines, avoiding overarylation, would have the largest impact on aryl(di)azinylmethane and bis(di)azinylmethane formation.

\section{Acknowledgement}

Financial support by the University of Antwerp (BOF), the Research Foundation - Flanders (FWO), the Agency for Innovation by Science and Technology (IWT) and the Hercules Foundation is gratefully acknowledged.

\section{References}

(1) (a) Hassan, J.; Sevignon, M.; Gozzi, C.; Schulz, E.; Lemaire, M. Chem. Rev. 2002, 102, 1359. (b) Stanforth, S. P. Tetrahedron 1998, 54, 263.

(2) Liegault, B.; Renaud, J.-L.; Bruneau, C. Chem. Soc. Rev. 2008, 37, 290 .

(3) (a) Bedford, R. B.; Huwe, M.; Wilkinson, M. C. Chem. Commun. 2009, 600. (b) Amatore, M.; Gosmini, C. Chem. Commun. 2008, 5019.

(4) Murugan, R.; Scriven, E. Pyridines: from lab to production; Elsevier: Amsterdam, 2013.

(5) Kleemann, A.; Engel, J.; Kutscher, B.; Reichert, D. Pharmaceutical substances, 4th ed.; Georg Thieme Verlag: Stuttgart, 2001.

(6) (a) De Houwer, J.; Abbaspour Tehrani, K.; Maes, B. U. W. Angew. Chem. Int. Ed. 2012, 51, 2745. (b) Itoh, M.; Hirano, K.; Satoh, T.; Miura, M. Org. Lett. 2014, 16, 2050. (c) Niwa, T.; Yorimitsu, H.; Oshima, K. Org. Lett. 2007, 9, 2373.

(7) (a) King, A. O.; Okukado, N.; Negishi, E.-i. J. Chem. Soc., Chem. Commun. 1977, 683. (b) Fauvarque, J. F.; Jutand, A. J. Organomet. Chem. 1977, 132, C17.

(8) Hargreaves, S. L.; Pilkington, B. L.; Russell, S. E.; Worthington, P. A. Tetrahedron Lett. 2000, 41, 1653.
(9) Khatib, S.; Tal, S.; Godsi, O.; Peskin, U.; Eichen, Y. Tetrahedron 2000, 56, 6753.

(10) Krapcho, A. P.; Ellis, M. ARKIVOC 2000, (i), 43.

(11) Andrés, J. I.; Alonso, J. M.; Fernández, J.; Iturrino, L.; Martínez, P.; Meert, T. F.; Sipido, V. K. Bioorg. Med. Chem. Lett. 2002, 12, 3573.

(12) Chekmarev, D. S.; Stepanov, A. E.; Kasatkin, A. N. Tetrahedron Lett. 2005, 46, 1303.

(13) (a) Štefko, M.; Slavětínská, L.; Klepetářová, B.; Hocek, M. J. Org. Chem. 2010, 75, 442. (b) Urban, M.; Pohl, R.; Klepetářová, B.; Hocek, M. J. Org. Chem. 2006, 71, 7322.

(14) Walters, I. A. S. Tetrahedron Lett. 2006, 47, 341.

(15) Vettel, S.; Vaupel, A.; Knochel, P. J. Org. Chem. 1996, 61, 7473.

(16) Brown, D. A.; Kharkar, P. S.; Parrington, I.; Reith, M. E. A.; Dutta, A. K. J. Med. Chem. 2008, 51, 7806.

(17) D'Angelo, N. D.; Kim, T.-S.; Andrews, K.; Booker, S. K.; Caenepeel, S.; Chen, K.; D’Amico, D.; Freeman, D.; Jiang, J.; Liu, L.; McCarter, J. D.; San Miguel, T.; Mullady, E. L.; Schrag, M.; Subramanian, R.; Tang, J.; Wahl, R. C.; Wang, L.; Whittington, D. A.; Wu, T.; Xi, N.; Xu, Y.; Yakowec, P.; Yang, K.; Zalameda, L. P.; Zhang, N.; Hughes, P.; Norman, M. H. J. Med. Chem. 2011, 54, 1789.

(18) Hall, A.; Billinton, A.; Brown, S. H.; Chowdhury, A.; Clayton, N. M.; Giblin, G. M. P.; Gibson, M.; Goldsmith, P. A.; Hurst, D. N.; Naylor, A.; Peet, C. F.; Scoccitti, T.; Wilson, A. W.; Winchester, W. Bioorg. Med. Chem. Lett. 2009, 19, 2599.

(19) Tynebor, R. M.; Chen, M.-H.; Natarajan, S. R.; O’Neill, E. A.; Thompson, J. E.; Fitzgerald, C. E.; O’Keefe, S. J.; Doherty, J. B. Bioorg. Med. Chem. Lett. 2011, 21, 411.

(20) Schade, M. A.; Metzger, A.; Hug, S.; Knochel, P. Chem. Commun. 2008, 3046.

(21) Metzger, A.; Schade, M. A.; Knochel, P. Org. Lett. 2008, 10, 1107.

(22) Manolikakes, G.; Muñoz Hernandez, C.; Schade, M. A.; Metzger, A.; Knochel, P. J. Org. Chem. 2008, 73, 8422.

(23) Błachut, D.; Szawkało, J.; Czarnocki, Z. Synthesis 2011, 3496.

(24) Chupak, L. S.; Wolkowski, J. P.; Chantigny, Y. A. J. Org. Chem. 2009, 74, 1388.

(25) Blümke, T. D.; Groll, K.; Karaghiosoff, K.; Knochel, P. Org. Lett. 2011, 13, 6440.

(26) Mori, K.; Maki, S.; Niwa, H.; Ikeda, H.; Hirano, T. Tetrahedron 2006, 62, 6272 .

(27) Flaherty, A.; Trunkfield, A.; Barton, W. Org. Lett. 2005, 7, 4975.

(28) St. Denis, J. D.; Scully, C. C. G.; Lee, C. F.; Yudin, A. K. Org. Lett. 2014, 16, 1338.

(29) Angiolelli, M. E.; Casalnuovo, A. L.; Selby, T. P. Synlett 2000, 905 .

(30) Metzger, A.; Melzig, L.; Despotopoulou, C.; Knochel, P. Org. Lett. 2009, 11, 4228.

(31) Melzig, L.; Metzger, A.; Knochel, P. J. Org. Chem. 2010, $75,2131$.

(32) Metzger, A.; Melzig, L.; Knochel, P. Synthesis 2010, 2853.

(33) Kofink, C. C.; Knochel, P. Org. Lett. 2006, 8, 4121.

(34) Chen, X.; Zhou, L.; Li, Y.; Xie, T.; Zhou, S. J. Org. Chem. 2014, 79, 230.

(35) Molander, G. A.; Elia, M. D. J. Org. Chem. 2006, 71, 9198.

(36) Kuwano, R.; Yu, J. Y. Heterocycles 2007, 74, 233.

(37) Botella, L.; Nájera, C. J. Organomet. Chem. 2002, 663, 46.

(38) (a) Maiti, D.; Fors, B. P.; Henderson, J. L.; Nakamura, Y.; Buchwald, S. L. Chem. Sci. 2011, 2, 57. (b) Biscoe, M. R.; Fors, B. P.; Buchwald, S. L. J. Am. Chem. Soc. 2008, 130, 6686.

(39) Schmink, J. R.; Tudge, M. T. Tetrahedron Lett. 2013, 54, 15. 
(40) Niwa, T.; Yorimitsu, H.; Oshima, K. Angew. Chem. Int. Ed. 2007, 46, 2643.

(41) Shang, R.; Yang, Z.-W.; Wang, Y.; Zhang, S.-L.; Liu, L. J. Am. Chem. Soc. 2010, 132, 14391.

(42) Campeau, L.-C.; Schipper, D. J.; Fagnou, K. J. Am. Chem. Soc. 2008, 130, 3266.

(43) Schipper, D. J.; Campeau, L.-C.; Fagnou, K. Tetrahedron 2009, 65, 3155 .

(44) Larivée, A.; Mousseau, J. J.; Charette, A. B. J. Am. Chem. Soc. 2007, 130, 52.

(45) Mousseau, J. J.; Larivee, A.; Charette, A. B. Org. Lett. 2008 , $10,1641$.
(46) Duez, S.; Steib, A. K.; Manolikakes, S. M.; Knochel, P. Angew. Chem. Int. Ed. 2011, 50, 7686.

(47) Burton, P. M.; Morris, J. A. Org. Lett. 2010, 12, 5359.

(48) Fairlamb, I. J. S.; Kapdi, A. R.; Lee, A. F. Org. Lett. 2004, $6,4435$.

(49) Song, G.; Su, Y.; Gong, X.; Han, K.; Li, X. Org. Lett. 2011, 13,1968

(50) Mai, W. P.; Yuan, J. W.; Li, Z. C.; Yang, L. R.; Xiao, Y. M.; Mao, P.; Qu, L. B. Synlett 2012, 23, 938.

(51) Youssif, S. ARKIVOC 2001, (i), 242. 